This item was submitted to Loughborough's Research Repository by the author.

Items in Figshare are protected by copyright, with all rights reserved, unless otherwise indicated.

\title{
Interactions between subgrid-scale resolution, feature representation and grid-scale resolution in flood inundation modelling
}

PLEASE CITE THE PUBLISHED VERSION

http://dx.doi.org/10.1002/hyp.7813

PUBLISHER

(C) John Wiley and Sons

VERSION

SMUR (Submitted Manuscript Under Review)

\section{LICENCE}

CC BY-NC-ND 4.0

\section{REPOSITORY RECORD}

Yu, Dapeng, and Stuart N. Lane. 2019. "Interactions Between Subgrid-scale Resolution, Feature Representation and Grid-scale Resolution in Flood Inundation Modelling”. figshare.

https://hdl.handle.net/2134/13024. 
This item was submitted to Loughborough's Institutional Repository (https://dspace.lboro.ac.uk/) by the author and is made available under the following Creative Commons Licence conditions.

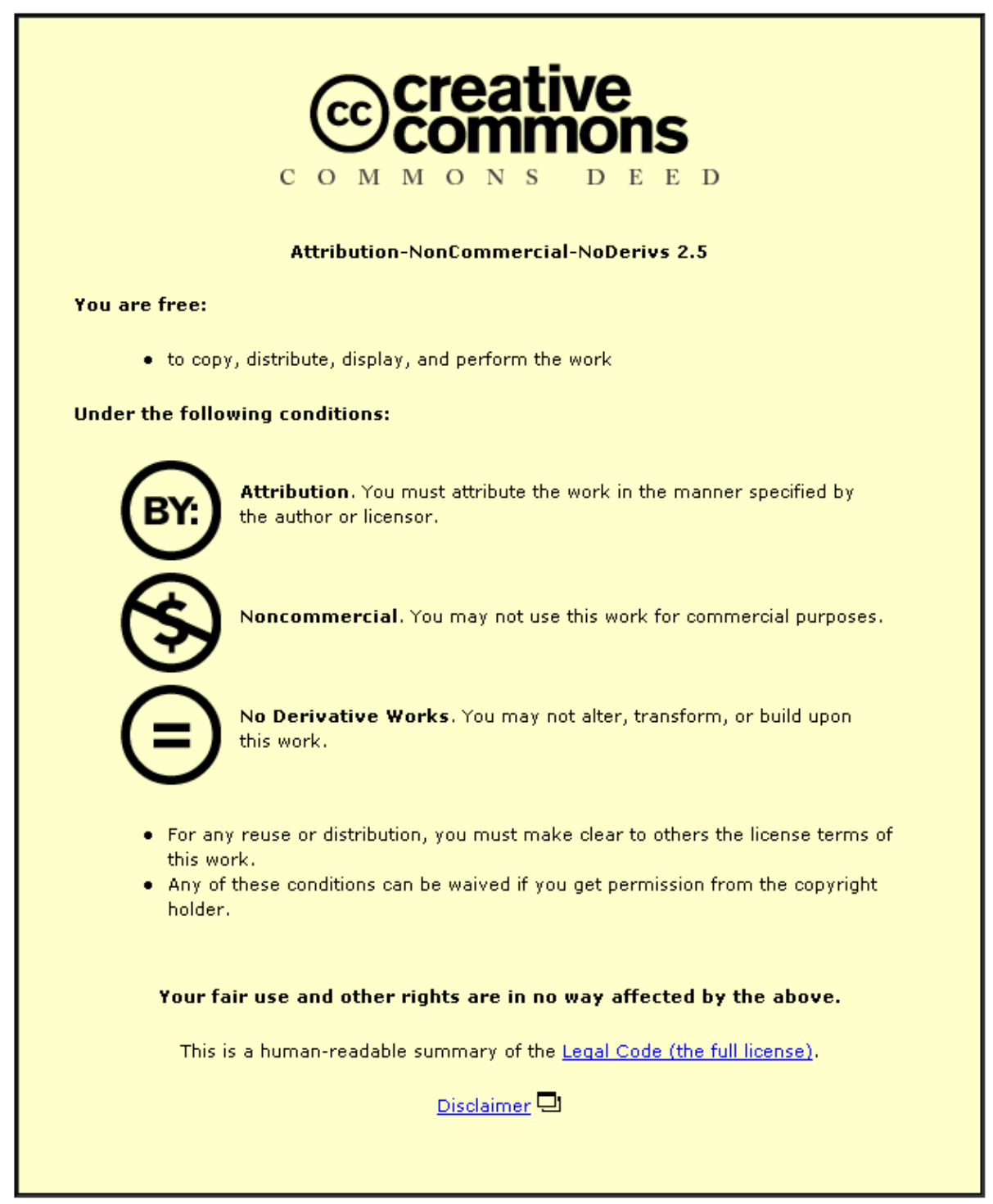

For the full text of this licence, please go to: http://creativecommons.org/licenses/by-nc-nd/2.5/ 
Interactions between sub grid-scale resolution, feature representation and grid-scale resolution in flood inundation modelling

\begin{tabular}{|r|l|}
\hline Journal: & Hydrological Processes \\
\hline Manuscript ID: & HYP-08-0229 \\
\hline Wiley - Manuscript type: & Research Article \\
\hline Date Submitted by the \\
Author: & 22-May-2008 \\
\hline Complete List of Authors: & $\begin{array}{l}\text { Yu, Dapeng; Loughborough University, Geography } \\
\text { Lane, Stuart; Durham University, Geography }\end{array}$ \\
\hline Keywords: & $\begin{array}{l}\text { fluvial flood modelling, diffusion-based modelling, sub grid scale } \\
\text { treatment, feature representation, spatial resolution }\end{array}$ \\
\hline
\end{tabular}

\section{ScholarONE \\ Manuscript Central}




\title{
Interactions between sub grid-scale resolution, feature representation and grid-scale resolution in flood inundation modelling
}

\author{
D. $\mathrm{Yu}^{1}$ and S.N. Lane ${ }^{2}$ \\ ${ }^{1}$ Department of Geography, Loughborough University, Loughborough, LE11 3TU \\ ${ }^{2}$ Institute of Hazard and Risk Research, Department of Geography, Durham University, Science \\ Laboratories, South Road, Durham DH1 3LE
}

\begin{abstract}
Numerical modelling of flood inundation over large and complex floodplains often requires mesh resolutions coarser than the structural features (e.g. buildings) that are known to influence the inundation process. Recent research has shown that this mismatch is not well represented by conventional roughness treatments but that finer scale features can be represented through porositybased sub grid scale treatments. This paper develops this work by testing the interactions between feature representation, sub grid scale resolution and mesh resolution. It uses as the basis for this testing a 2D diffusion-based flood inundation model which is applied to a 2004 flood event in a topologically-complex upland floodplain in northern England. Results showed serious degradation of model predictions without explicit representation of features like walls. Inclusion of such features through raising mesh cell elevations where intersected by a feature resulted in a major improvement in model predictions in terms of reduced inundation extent. To make such treatments physically realistic, and notably so that the full potential for floodplain storage is included, it was shown that a sub grid scale treatment also needed to be included. The effects of this combined treatment was the recovery of more plausible floodplain friction values as well as a sensitivity to friction that allows for more effective representation of floodplain friction effects such as vegetation.
\end{abstract}

KEY WORDS: fluvial flood modelling; diffusion-based modelling; sub grid scale treatment; feature representation; spatial resolution 


\section{INTRODUCTION}

Fluvial flood modelling in both rural and urban areas has been shown (Dutta, et al., 2007; Mignot et al., 2006; Yu and Lane, 2006a, 2006b; Tayefi et al., 2007) to require explicit representation of smallscale topographic variation in order to capture the patterns of flux near structural elements (e.g. walls, buildings and railroads, etc). Such elements are commonly represented in two-dimensional models explicitly as far as the model resolution allows, with sub grid scale features represented by upscaling momentum losses, usually using a friction parameter. However, a number of studies have demonstrated the severe sensitivity of such modelling approaches to mesh resolution (e.g. Horritt \& Bates, 2001a, b; Yu and Lane, 2006a) and that neither roughness upscaling (e.g. Yu and Lane, 2006a; Neelz and Pender, 2007) nor a wetting parameter (e.g. Bradbrook et al., 2004; Yu and Lane, 2006a) are sufficient to represent the effects of structural elements, especially where the floodplain is complex. The basic reason for this is that changes in mesh resolution simultaneously change the topographic information content of the surface being modelled (Bates and Anderson, 1996; Marks and Bates, 2000). This impacts upon the way that flow is blocked and routed, rather than just the speed with which the wetting front moves across the floodplain. Here we take topography to include both natural features (e.g. river terraces) and anthropogenic features (e.g. buildings, walls).

The rapid development of remote sensing of floodplain surfaces over the last 10 years (e.g. Marks and Bates, 2000; Mason et al., 2003) has meant that the limitations imposed by data availability over large areas are less significant than those associated with the numerical constraints upon simulation extent. Modelling large floodplains still requires mesh resolutions coarser than the features (e.g. walls, buildings) that influence the flow routing process, and it is likely that sub grid-scale treatments of topographic detail finer than the chosen mesh resolution will remain necessary. One solution to this has been roughness upscaling (e.g. Horritt and Bates, 2001a, b; Yu and Lane, 2006a) and progress has been made in the derivation of spatially-distributed roughness values derived either from remotely sensed land cover data (e.g. Wilson and Atkinson, in press) and from airborne scanning laser altimetry 
(e.g. Mason, et al., 2003; Mason, et al., 2007). Aside from the fact that sensitivity to floodplain friction is relatively low, often necessitating values of friction greater than those used to parameterise the original friction representation, friction treatments only represent the effects of momentum loss and not mass blockage (Lane, 2005). Thus, effort has been put into representing floodplain roughness using alternative methods, and notably explicit parameterisation of mass blockage (e.g. Yu and Lane, 2006b; McMillan and Brasington, 2007; Soares-Frazao et al., 2008), such that the effects of flow routing upon the movement of the flood wetting front is represented more effectively. Yu and Lane (2006b) explored sub grid treatments with a mesh resolution that followed a dyadic series (i.e. $r^{2} 2^{n}$ ), for $n=0$ to 3 , where $r$ is the finest resolution of data available, in their case, $2 \mathrm{~m}$. For each mesh resolution defined by $n$ (except for $\mathrm{n}=0$ ), they assessed the effects of sub grid scale treatments with a resolution of $2^{n+m}$ for $m=1$. They found that use of a sub grid scale treatment significantly improved model performance, but did not consider the situation where $m>1$. In this paper, we assess the effects of situations where $m>1$, as an attempt to begin to identify just how coarse a model resolution can become, whilst still retaining a reasonable representation of the effects of floodplain elements upon the flood inundation process. We include in the effects of topographic post-processing upon the representation of floodplain features as the averaging process used to determine the elevations of cells in coarser meshes can often smooth these features out of the analysis.

\section{METHODOLOGY}

Our method develops the treatment presented by Yu and Lane (2006b) which tested the effects of mesh resolutions $r^{2} 2^{n}$, for $n=0$ to 3 and sub grid scale resolutions $2^{n+m}$ for $m=1$. The basis of the model used is described in Bradbrook et al. (2004) and Yu and Lane (2006a). Here, we restrict description of the process representation for situations where $m>1$. Mesh coarsening impacts upon both numerical solution and the topographic content of the model. In terms of the latter, coarsening has two effects, depending upon how the topographic information is represented in a coarser mesh. First, the simplest and most often adopted coarsening simply averages all the sub grid scale 
topographic information in the coarser mesh. As the surface wets, this means that water, in reality, may be able to flow into the area represented by the cell if the area has locations lower than the average. This is a cell blockage, introduced by averaging, that impacts upon mass balance calculations. Second, and more importantly, the arrangement of elevations within a cell will control where water is able to flow. As the elevations are averaged, and especially where $m>1$, it is reasonable to assume that possible flow paths and blockages to flow become averaged out of the surface. This can have a dramatic impact upon the ease of diffusion of flood water across a floodplain.

\section{Cell blockage effect}

The cell blockage effect can be generalised as:

$$
V_{i j}=\frac{R^{2}}{2^{2 m}}\left(n_{w} H_{i j}-\underset{k=1}{n_{w}}, e_{k}\right)
$$

where $V_{i j}$ is the volume of water in the mesh cell $i j$ which has a resolution of $R ; n_{w}$ is the number of sub grid scale cells that are wet; $H_{i j}$ is the elevation of the water in cell $i j$; and $e_{k}$ is the bed elevation of the sub grid cell $k$. Inspection of [1] shows that when the cell is fully wet, $n_{w}$ becomes equal to the total number of sub grid cells (i.e. $2^{2 \mathrm{~m}}$ ) and the volume of water in the cell is effectively represented by the average elevation of the sub grid cells. Thus, it is where $H_{i j}<\max \left(e_{k}\right)$ that the cell blockage effect creates an error in the available volume of the coarser cell for inundation. For each sub grid cell resolution $R / 2^{m}$, the extent of this effect will increase as $m$ increases in relation to the variability in the set of $e_{k}$ values at each $m$. Thus, our first correction is to evaluate water volume using [1]. This is identical to $\mathrm{Yu}$ and Lane (2006b), but uses situations where $m \geq 1$ rather than $m=1$. It is important to note that, in order to speed up computation time, DEM pre-processing for a range of $H_{i j}$ values for each cell is necessary. 


\section{Cell flux effect}

The second correction controls for sub grid-scale effects upon the flux across cell faces. Cell flux is calculated using a porosity-type treatment which has proved to be a powerful means of representing sub grid scale topographic effects in river flows (e.g. Olsen and Stokseth, 1995; Lane and Hardy, 2002; Lane et al., 2002; Lane et al., 2004) and for representation of wetting and drying processes in depthaveraged hydrodynamic models of floodplain inundation (e.g. Bates, 2000). The procedure of calculating the porosity of a common face is based upon the Yu and Lane (2006b) treatment for $m=1$, where each face has two sub grid-scale cells. The assumption made here is that flux should only occur across the face between two cells when a sub grid scale cell in cell 1 is wet and the water surface in that sub grid scale cell is higher than that the adjacent sub grid cell in cell 2 . Thus, the first step is to establish a set of rules that determine when flux can occur across the common face of cell 1 and 2, and this has to be done in both directions (i.e. for flux from cell 1 to 2 and from cell 2 to 1 ). A porosity term is set based upon the percentage of cells that will be able to flux from cell 1 to 2 along the common face of cell 1 and cell 2, which varies as a function of $H_{i j}$. If the number of sub grid-scale cells along a common face is $2^{m}$, total face porosity will be based upon evaluation of $2^{m}$ values. For the case of flux from cell 1 to 2 , the porosity values are set by evaluating two conditions: (a) the water surface elevation values that must be reached in cell 1 for there to be water in a given sub grid cell in cell 1; and (b) the elevation of the adjacent grid cell in cell 2, which must be exceeded by the water surface elevation value of the in cell 1 for their to be a sub grid scale flux. If both (a) and (b) are met, the water surface elevation of each sub-grid cell in cell 1 along the common face is compared to its adjacent sub grid cell in cell 2 . The porosity of cell 1 to cell 2 is calculated as the total number of sub grid cell in cell 1 along the common face that has a water surface elevation higher than its adjacent sub grid cell in cell 2 divided by the total number of sub grid cells along the common face, i.e. $2^{m}$. Therefore, the porosity from one grid cell to another can vary between 0 (100\% blockage) and 1 (0\% blockage). The porosity values are used to scale the flux explicitly. 
One additional correction was introduced in the modified FloodMap (Yu and Lane, 2006b). As the flux is a non-linear function of water depth (from the Manning equation), then we need to make sure that the correct water depth is used in the evaluation of flux. This is done by determining an effective depth for the flux, based upon:

$d_{e}=\sqrt[3 / 5]{\frac{\sum_{i=1}^{n} d_{i}^{5 / 3}}{n}}$

where $n$ is the number of sub grid cells that are wet along the outflow side of the modelling cell and $d_{i}$ is the effective depth of the individual sub grid wetted cells along the outflow wall of the modelling cell. If flux occurs across one sub grid cell face, then the flux evaluated using [2] with the porosity scaling gives the same flux as if a mesh set at the sub grid scale resolution was being adopted. This is not the case when more than one sub grid scale flux occurs because of the non linear form of the depth-flux relationship in the Manning equation. However, provided the topographic variability within fluxing sub grid scale cells is small then the error is small, and the weighting used in [2] further reduces this error. This approach differs from the wetting and drying parameter developed by Bradbrook et al. (2004) and used in Yu and Lane (2006a, b) in that their wetting and drying parameter represents an empirical means for dealing with mesh resolution effects without taking into account the cell blockage and cell flux effect described above. The sub grid approach developed here is explicitly grounded in rules that are locally evaluated in relation to information on the sub grid scale topography in a particular grid cell.

\section{Froude number control on effective depth}

In this application, we are using a 2D diffusion-based flood inundation model. This assumes that the inertial terms are negligible, an assumption that is only valid if flow velocities are relatively low. In 
such models, flow velocity is implicitly controlled by effective water depth, cell size and Manning's $n$ as expressed in (equation 3):

$$
v=\frac{d^{0.5+R}}{w^{1 / 2}}
$$

Where $R$ is the exponent of hydraulic radius. The exponent of hydraulic radius is set to be $2 / 3$ as an approximate value in the original Manning equation. The derivation of the exponent of hydraulic radius was derived from experimental data on artificial channels. Manning noted that the mean value of the $R$ exponent in Manning Equation is not a true constant and varies (1891). The average value of the exponent was found to vary from 0.6499 to 0.8395 for different shapes and roughness of channels (Manning, 1891). Chow (1964) argued that a value of $3 / 4$ or a variable exponent should be used. Many studies have shown that $n$ typically decreases with increasing hydraulic radius (e.g. Azmon, 1992; Leonard et al., 2000). Hydraulic radius in the 2D diffusion formulation is the depth of the water in a single cell. This implies 2D diffusion-based formulation may require a variable hydraulic exponent should Manning's $n$ be used. Simulations were undertaken to test this parameter. It was found that the model sensitivity to this parameter is extremely low. Thus, this will not be used as a calibration parameter in this study.

Therefore, velocity is essentially determined by mesh discretization ( $w)$ and floodplain roughness $(n)$ in diffusion based approaches, controlled by effective depth $(d)$. Flow in a coarser mesh will generally be faster than that in a finer mesh. Equation (3) also shows the effect of roughness specification on flood inundation. Floodplain with a higher roughness value will result in slower flow and vice versus. Given the same roughness characteristic, questions arise as to whether a finer mesh will result in a better prediction. Apart from mesh size and roughness, the effective depth is a dynamic parameter that is spatially and temporally variable. Over topographically complex floodplains, super-critical flow is likely to occur in isolated places, largely due to the abrupt change in ground elevation associated with 
structural features (e.g. walls in this case). In such situations, exceptionally high velocity will occur. This has three implications for the model. First, as the optimum time step for the next time step is calculated based on the Courant condition ( $\mathrm{Yu}$ and Lane, 2006a) where the velocity used is the maximum velocity found in the current time step, exceptional high velocity will reduce the time step significantly. Second, flux calculated based on the diffusion model will be considerably high which may cause check-board effect (Hunter et al., 2006). Third, and most importantly, diffusion wave approximation is theoretically best applicable to low slopes with $\mathrm{Fr}$ number smaller than 1 . Therefore, a modification was made to the model to account for the influence of effective depth on flow velocity. This is based on a Froude number condition. The maximum effective depth between cells is set such that the flow is kept at the subcritical state. This prevents sudden changes in water depths due to high effective depths at places where there are abrupt changes in topography. The maximum effective depth for a specific mesh resolution and roughness specification is calculated using this equation:

$d<w^{3 / 4} g^{3 / 4} n^{3 / 2}$

When an effective water depth between two cells calculated based on water surface elevations exceeds the maximum effective depth, the effective depth is scaled down to this maximum effective depth. A number of advantages are offered by this approach. Firstly, the adoption of this parameter to a large extent eliminates the check-board effect associated with complex topography in $2 \mathrm{D}$ diffusion based models (Hunter et al., 2006). Secondly, according to equation [4], the maximum velocity will occur at the maximum effective depth. Cascading of the maximum velocity can result in a near-monotonic decrease in time step during the simulation. The maximum effective depth condition imposed by equation [4], in combination with the Courant number condition described in Yu and Lane (2006a), is usually sufficient to obtain the optimum time step with a stable solution. This parameter is more likely to be applied to the finer meshes in that: (i) the maximum effective depth for a finer mesh is proportional to $w^{3 / 4}$; and (ii) the smoothing effect of mesh coarsening reduces the possibility of abrupt changes in topography. 


\section{MODEL APPLICATION}

\section{Study site and data source}

Tests for $m \geq 1$ were carried out for a reach of rural floodplain in northern England: the upper River Wharfe, UK. This is a typical upland gravel-bed river with complex floodplain topography, characterized by networks of dry stonewalls (Figure 1), hedges and fences. This study focuses in particular on the effects of dry stonewalls. These features are largely impervious during flood, except in places where there are gates in between. These walls were observed to exert an important control on flood routing (Tayefi et al., 2007). Therefore, it is recognized that representing these features is essential for the representation of flow routing on the floodplain. It is also a site with good floodplain topographic data (LiDAR), well-established boundary conditions and reliable data on the maximum inundation extent during a 1:2 year flood event in February 2004.

Floodplain topography is represented with digital elevation models of different mesh resolution: $4 \mathrm{~m}$, $8 \mathrm{~m}, 16 \mathrm{~m}$ and $32 \mathrm{~m}$. The $4 \mathrm{~m}$ mesh was interpolated using bilinear interpolation to produce the coarser meshes. In this paper, we explore resolutions of $8 \mathrm{~m}, 16 \mathrm{~m}$ and $32 \mathrm{~m}$, with sub grid scale treatments of $4 \mathrm{~m}, 8 \mathrm{~m}$ and $4 \mathrm{~m}$, and $16 \mathrm{~m}, 8 \mathrm{~m}$ and $4 \mathrm{~m}$ respectively. To simplify reference to these, we refer to them as ratios: i.e. an $8 \mathrm{~m}$ mesh with a sub grid scale of $4 \mathrm{~m}$ is a 2:1 ratio. These are summarised in Table 1.

\section{Boundary conditions}

The flood lasted for 22 hours. However, only the first 10 hours of the flood, as the floodplain wetted, were used. As this was a 1:2 year event, it did not fully occupy the floodplain. Furthermore, this allows a large number of simulations to be carried out.

Two-dimensional flood inundation modelling has traditionally adopted a tightly coupled modelling approach, i.e. the river flow and floodplain flow is solved simultaneously at each time step (e.g. 
Horritt and Bates, 2001a, b; Yu, 2005). This approach is not suitable for the comparative evaluation of simulations with different sub grid treatment proposed in this paper in that it will not necessarily guarantee that the same amount of water is routed onto the floodplain for each simulation. In the 2D diffusion approach, flow routing at the river channel and floodplain boundary requires an additional boundary condition which itself will be sensitive to mesh resolution. To control for this, we use a loosely-coupled approach: i.e. river flow is solved prior to floodplain routing; aided by the observation that during the wetting phase, return flow to the main channel was negligible. In order to route the same amount of water onto the floodplain for simulations with different meshes and sub grid representation of floodplain topography, the river channel was divided into sections retained for each simulation. Each section has a unique flow hydrograph. In this study, the hydrographs for different sections were obtained from a 1D river flow model HEC-RAS. A flow hydrograph contains flow rate $\left(\mathrm{m}^{3} / \mathrm{s}\right)$ from a particular river session to the floodplain. This ensures the objective evaluation of the sub grid treatments given the same boundary condition from the river channel.

\section{Manning's $n$ and exponent of hydraulic radius}

This study also investigated the role of Manning's $n$. Following the findings of Yu and Lane (2006a, b), simulations with both lower (0.04. 0.06, 0.08 and 0.1) and higher (1.0 and 10.0) values of $n$ were undertaken to investigate the interaction between roughness specification and sub grid treatment with high sub grid mesh ratio.

\section{Model validation and verification}

In this study, model testing combines both validation and verification. Model validation involved comparing model prediction with observed maximum inundation extent. Increasingly over the last decade, distributed validation data such as synoptic inundation extent have been used to validate model prediction from various sources including post-event trash line surveys, aerial photos, airborne and satellite Synthetic Aperture Radar (SAR) data and post-event LiDAR survey of flood deposits (Hunter, 2007). Some of the data are point at-a-time (e.g. aerial photos and SAR) while others are 
collected after the event (e.g. trash line survey and flood deposit survey). It is recognized that the use of at-a-point validation data may be misleading in some situations (Yu and Lane, 2006a, b), e.g. when the validation time is long after a laterally-confined floodplain is fully inundated. In this study, maximum inundation extent during the flood was obtained by field survey of wrack lines (Tayefi et al., 2007) and, as it was only a 1:2 year flood event, the maximum floodplain inundation was not reached during the event. This provides validation data for this study. Post-event wrack line can be misinterpreted due to uncertainty during collection of data. To overcome the limitations of using such data, this study also undertook model verification wherein the predicted inundation extents over time are compared with a series of corresponding reference extents. The reference extents used in this study are those predicted by the finest mesh simulation, i.e. the $4 \mathrm{~m}$ simulation. The choice of reference extents does not imply that the finest mesh will necessarily result in best predictions given the sensitivity of model prediction to mesh resolutions. However, given that the focus of this paper is comparative studies, any reference dataset should produce the same results. Verification against a reference dataset over time to a large extent overcomes the limitation associated with validation using at-a-point data. Following Yu and Lane (2006a, b) three accuracy statistics are calculated for each simulation, i.e. overall accuracy, conditional Kappa for wet cells and the $F$ statistic. Overall accuracy is calculated as the sum of correctly predicted cells divided by the total number of cells in the domain. The main disadvantage with this statistic is that it is strongly dependent upon the number of mesh cells used in the computation in relation to the maximum inundated area as the latter is used as the denominator in the equation: the statistic may appear to do very well if the number of dry cells, that are never wetted but are always both observed and predicted as dry is large. Conditional Kappa for wet cells is derived from a discrete multivariate technique called Kappa analysis (Bishop et al., 1975) and is often cited as a more reliable measure of accuracy or agreement than overall accuracy (Cohen, 1960). The $F$ statistic is calculated as the number of cells both predicted and observed as wet divided by the total number of cells that are either predicted or observed as wet (e.g. Horritt and Bates, 2001a, b). The $F$ statistic is particularly suitable for assessing predictions of flood inundation as it focuses on how the model-predicted wet areas agree with validation dataset. 


\section{RESULTS AND DISCUSSION}

\section{Effect of dry stone walls on inundation extent over time}

In the $4 \mathrm{~m}$ mesh, the topographic information associated with walls are preserved explicitly: Linear cells can be identified from the DEM as continuous elevated cells. The inundation extent over time predicted using the $4 \mathrm{~m}$ mesh with a Manning's $n$ of 0.06 is shown in Figure 2. This maps the water depth and the locations of walls over time. These images shows immediately the effect of walls upon flood inundation. At the initial wetting stage, water flow is highly controlled by the walls. Notably, upstream of the river, for the first 4 hours of the flood, flow is constrained in compartments formed by walls near the river bank. Until the walls are submerged, water can only flow out of the compartments through gates in between. As the water depths increase, some of the walls become submerged, particularly downstream of the reach. Water depths at locations where walls are submerged are notably lower, indicated by linear cells with faded tones. This implicitly recognizes the mass storage effect of these structural features. The higher resolution view of the upper reach of the inundation map at $4.0 \mathrm{hrs}$ reveals that flow paths are highly channelled by structural features (Figure 3). On the right bank of the river, water depth is relatively low. Therefore, flow is constrained by the walls. Gates in between walls allow water to flow out of the compartment. As the mesh is coarsened from $4 \mathrm{~m}$ to $8 \mathrm{~m}$, $16 \mathrm{~m}$ and $32 \mathrm{~m}$ resolutions, the walls are gradually averaged out during interpolation. Some of the walls can still be identified from the $8 \mathrm{~m}$ mesh. But in the $16 \mathrm{~m}$ and $32 \mathrm{~m}$ meshes, no walls are discernable. Consequently, this is reflected in the simulation results. Flow becomes increasingly less controlled by the network of walls simply because the topographic information contained in these features is smoothed out in the coarsened meshes.

\section{Effect of sub grid scale treatments with coarser meshes}

The effect of sub grid treatments was investigated by comparing the inundation areas over time. Figure 4 shows the inundation areas over time for all resolutions and their sub grid simulations, compared with the default $4 \mathrm{~m}$ simulation. Two observations emerge here. First, the results are in line 
with the findings from previous studies in terms of the strong model sensitivity to mesh resolution (e.g. Horritt and Bates, 2001a; Yu and Lane, 2006a). All meshes over-estimate inundation extents compared to the $4 \mathrm{~m}$ mesh simulation throughout most of the simulation. Second, in all cases, sub grid treatment results in reduced inundation extents. Furthermore, for all resolutions, a higher sub grid mesh ratio further reduces inundation extents. This is also confirmed by visualisation of the inundation extents over time. The reason for this is that higher-ratio sub grid mesh contains more topographic information on the walls compared to the default model mesh. With the sub grid mesh coarsening ratio increases from 2:1 to $4: 1$ and then 8:1, topographic content associated with structural features represented in the model through the sub grid mesh will be increased, thus resulting in reduced inundated areas.

The normal practice for generating a coarser mesh is to interpolate a finer mesh. The simulations presented so far have used bilinear interpolation to generate the $8 \mathrm{~m}, 16 \mathrm{~m}$ and $32 \mathrm{~m}$ meshes from the $4 \mathrm{~m}$ mesh. During interpolation, topographic variability will be reduced and structural features may be smoothed out. Indeed this is the case for the walls investigated in this study (Figure 1): their representation gradually decreases as the mesh is coarsened. In order to include the effect of walls on flow routing, the directly interpolated meshes used above were post-processed to introduce the walls into the floodplain surface topography, by raising the ground elevation of the cells where walls are present to the corresponding elevation identified from the $4 \mathrm{~m}$ mesh. To evaluate the effect of the post-processing on flood inundation, Figure 5 compares the inundation extents from 3 hrs to 4.5 hrs for the $32 \mathrm{~m}$ mesh with and without walls. The results suggest that, with walls included explicitly, water diffuses much slower than its counterpart in the simulations with directly interpolated topography. Inundation area over time for all mesh solutions (Table 1) is plotted in Figure 6. Overall, there is less inundation with the post-processed meshes as compared to the directly-interpolated meshes. Furthermore, comparing Figure 6 with Figure 4, less sensitivity of inundation extent to mesh resolution is found when walls are included. Contrary to Figure 4, where a higher sub grid mesh ratio indeed reduces inundation extent, with walls built into the topography we see mixed results for the 32 
$\mathrm{m}$ simulations with different sub grid mesh ratios (Figure 6). For the $16 \mathrm{~m}$ simulations (Figure 6c), results from different sub grid ratios are also less discernable compared to the results in Figure 4. To a significant extent, explicit representation of floodplain features slows down the flow, especially for the coarser meshes. Topographic information associated with walls will gradually be reduced with directly-interpolated coarser meshes, in particular for the $16 \mathrm{~m}$ and $32 \mathrm{~m}$ meshes. Therefore, the sensitivity of the model to mesh resolution in terms of inundated areas is increased for the normal treatment. This also has implications for the sub grid treatment where post-processed sub grid meshes contain more wall-related topographic information than the directly-interpolated meshes. Thus, the sub-grid treatment shows a similar response to the normal treatment, i.e. reduced sensitivity with postprocessed meshes with walls re-introduced. For example, for the $8 \mathrm{~m}$ mesh, Figure $6 \mathrm{~d}$ shows that, for the $8 \mathrm{~m}$ simulations, the difference between the sub grid treatment and the normal treatment is marginal. However, the difference is much more pronounced with the directly-interpolated $8 \mathrm{~m}$ mesh (Figure 4d). This has two bearings. First, even for a mesh with a 2:1 coarsening ratio, the topographic complexity associated with walls will be reduced in a directly-interpolated mesh, resulting in smoother topography, thus more inundation. Only when the topographic complexity is built into the 8 m mesh explicitly, can the default mesh produces reduced inundation. Second, a directly-interpolated $8 \mathrm{~m}$ mesh with 2:1 sub grid topography gives similar results to a post-processed $8 \mathrm{~m}$ mesh with the same sub grid topography. This implies that the sub grid treatment is more effective in reducing inundation with a coarser mesh. For example, for the post-processed $16 \mathrm{~m}$ and $32 \mathrm{~m}$ meshes, there is a remarkable reduction in the inundation area for all ratios of sub grid treatment (Figure 6b, 6c) as compared to the directly-interpolated meshes (Figure 4b, 4c).

Representing structural features by simply raising cell elevations is questionable, in particular for a coarser mesh. It is physically unrealistic as the dimension of a single cell in such a mesh is usually much wider than these of the structural features in reality (e.g. Bates et al., 2006). Indeed, even representing walls in the $4 \mathrm{~m}$ DEM using linear cells is problematic given that the dimension of these features is unlikely to be larger than $4 \mathrm{~m}$. Furthermore, this would potentially reduce the available 
floodplain storage by a significant amount. In terms of floodplain storage, simply raising averaged ground elevations of wall-intersected cells is likely to introduce large mass balance errors, i.e. large areas of floodplain that could otherwise be inundated are not allowed to become inundated. The sub grid treatment approach addresses these problems by representing structural features implicitly in the sub grid topography, thus allowing realistic representation while maintaining mass storage effect associated with such features. A potential way to represent discontinuity associated with such features might be the fusion of both raster representation and vector representation in the model.

\section{Model validation}

Table 2 shows the results of model validation obtained with the simulations listed in Table 1 for both the directly-interpolated meshes and the post-processed meshed with walls re-introduced. Results show that all the simulations produced quite good predictions of maximum inundation extent for overall accuracy and conditional Kappa for wet cells. But the $F$ statistics are not particularly high. For the normal treatment, there is no obvious difference (within 1\%) in all the statistics for all mesh resolutions. It seems validation does not distinguish between meshes with different topographic content. Sub grid simulations with all mesh ratios perform better than or equally to the corresponding normal treatment. However, the difference in the accuracy statistics between different mesh ratios is generally low. The sensitivity observed in both Figure 4 and Figure 6 in terms of inundation area to different mesh resolution for the normal treatment as well different mesh ratios of the sub grid treatment is not reflected in the accuracy statistics obtained from validation. This may due to the type of validation data that we use to evaluate the model. This emphasises the drawback of using point-intime validation data to evaluate performance of distributed models of this type (e.g. Yu and Lane, 2006a; Hunter et al., 2007). In this case, maximum inundation extent is not particularly useful for assessing different model formulations in that it will not allow evaluation of model performance before the maximum inundation extent is reached. 
Given that model validation did not distinguish between model simulations in terms of their performance, model verification was carried out whereby comparative studies can be made with regards to model performance over time as compared to a reference dataset. Model verification used predictions from the $4 \mathrm{~m}$ simulation as the reference dataset, and compared the inundation extents obtained from all other simulations back to the $4 \mathrm{~m}$ data. This is effectively a check on the extent to which introducing treatments, such as the sub grid-scale treatment, reduce the sensitivity to mesh resolution. For each simulation, accuracy statistics were calculated by comparing the results with the 4 $\mathrm{m}$ predictions at a 5-minute interval. This generates the accuracy statistics of each model prediction over the whole simulation period. Figure 7 shows the results in terms of the overall accuracy, Kappa for wet cells and $F$ statistic. A number of observations emerge from the results. First, the general pattern for all categories of statistics over time, is that the finer the mesh, the better the statistical values of accuracy, though with some exceptions during the initial wetting process (i.e. before $c$. 2.5 hrs). Second, the sub grid treatment outperforms the simulation with default resolution for all mesh resolutions, in particular for the period of rapid inundation (c. $2.5 \mathrm{hr}-5 \mathrm{hr}$ ). Third, higher sub grid mesh ratios further improve the predictions. This is particularly obvious for the $F$ statistic (Figure $7 c$ ). We compares the $F$ statistics of simulations obtained from the directly-interpolated meshes (Figure 7c) with these obtained from simulations with walls explicitly built in (Figure 7d). In the absence of influence from extensive topographic controls imposed by networks of walls the sub grid treatment shows higher sensitivity to mesh ratio (Figure 7c). This is reduced when the walls are introduced in the meshes. Similar to the analysis of inundation areas (Figure 4 and Figure 6), the relatively low improvement obtained with the higher ratio sub grid mesh in the latter case (Figure 7d) is due to the fact that the meshes used contain more topographic information on the walls. These features essentially represent topological barriers to the flow at different stages of the flooding, modifying the flow behaviour which would otherwise occur in smoother floodplains (Figure 7c). In other words, the effects of both mesh resolution and sub grid treatment with different mesh ratios were dwarfed by the re-introduction of walls into the topography. 


\section{Effect of Manning's $n$}

Given the model's strong sensitivity to mesh resolution, the obvious question is whether this can be reconciled through adjustment of Manning's $n$. This was tested using the interpolated topographies. Following Yu and Lane (2006a, b), both low $(0.04,0.06,0.08,0.1)$ and high (1.0 and 10) values of Manning's $n$ were tested. Figure 8 compares the inundation areas over time obtained with different Manning's $n$ values for the $4 \mathrm{~m}, 8 \mathrm{~m} 16 \mathrm{~m}$ and $32 \mathrm{~m}$ simulations with and without the sub grid treatment. In each plot, the inundation area is compared with the $4 \mathrm{~m}$ simulation with a $n$ value of 0.06 . In line with previous findings ( $\mathrm{Yu}$ and Lane, 2006a, b), the model shows very low sensitivity to low Manning's $n$ values $(0.04,0.06,0.08$ and 0.1$)$ which are broadly within the Chow et al.'s range of Manning's $n$ values (1988). Roughness specification only starts to have a noticeable effect on flow routing with a much higher value of 1.0. It is apparent that we can increase $n$ to reduce inundation extent. However, due to the low sensitivity of $n$, the required increase in $n$ could be very high, well beyond of the range of values within which Manning equation was originally formulated.

For the simulations with a $32 \mathrm{~m}$ (Figure 8a) or $16 \mathrm{~m}$ (Figure 8e) mesh and the normal treatment, the $n$ value of 1.0 best approximates the inundation area predicted by the $4 \mathrm{~m}$ simulation with an $n$ value of 0.06 over time. This agrees with the results from Yu and Lane (2006b) where a Manning's $n$ value of 1.0 was also found to best approximate the $4 \mathrm{~m}$ simulation results. However, for the $8 \mathrm{~m}$ simulation (Figure 8i), the low values of $n(0.04-0.01)$ produced better approximation to the $4 \mathrm{~m}$ results than an $n$ value of 1.0 or 10 .

With the sub grid treatment, a lower value of $n$ is required to reproduce the $4 \mathrm{~m}$ results. For example, the $32 \mathrm{~m}$ mesh with a $16 \mathrm{~m}$ sub grid mesh and an $n$ value of 1.0 brings the corresponding curve closer to the $4 \mathrm{~m}$ simulation, as compared with $n=1.0$ in the default $32 \mathrm{~m}$ simulation. The effect of sub grid treatment in approximating the $4 \mathrm{~m}$ inundation gradually increases with a higher sub grid mesh ratio. For example, the sub grid simulation with a $32 \mathrm{~m}$ mesh and a mesh ratio of 8:1 (Figure 8d) improves the agreement with the $4 \mathrm{~m}$ inundation extents over time even with relatively low values of roughness 
in the range between 0.04 and 0.1 as compared to the 4:1 (Figure 8c) and 2:1 (Figure 8b) mesh ratios. In other words, where it is possible for $m$ to be $>1$, using $m>1$ is a means of allowing values of floodplain friction to be used that are more within the range for which the friction rule was developed. There is also greater sensitivity to floodplain friction as a result, which means that parameterisation of other floodplain friction effects, such as vegetation, should become more straightforward.

\section{CONCLUSION}

This study investigated the interaction between sub-grid scale treatment of floodplain features, postprocessing of the floodplain surface in order to represent those features and parameterisation of subgrid scale effects using roughness parameterisation. This emphasises the dominant effects of postprocessing to introduce the topological controls associated with structural features. With the topological effects (i.e. connectivity between elements) being particularly important, it is necessary to post-processing in order to retain such features. However, particularly in relatively coarse meshes, introducing linear features by raising cell elevations may not be physically realistic and this may reduce the potential storage volume that is available on the floodplain. The analysis of the sub grid treatment showed that using as much sub grid scale information as possible in coarser meshes did improve model predictions with respect to a verification dataset, although the magnitude of this improvement was relatively small. However, its impacts were dwarfed by the effects of postprocessing to include, in this case, the topological complexity arising from walls on the floodplain. As this post-processing was achieved by explicitly raising floodplain cells at their intersection with these floodplain features, modelling this floodplain with particularly coarse meshes is only meaningful with a sub grid scale treatment to make it physically realistic. The clear recommendation here for floodplain inundation studies is that floodplain features such as buildings and walls should be retained in the high resolution data used to parameterise a sub grid scale model, and not used, simply, to raise the elevation of coarser resolution mesh cells. Our results are particularly encouraging as by combining the sub grid scale correction and retaining the detailed elevation of floodplain features, it 
was possible to use more meaningful Manning's $n$ values, and to recover a sensitivity to $n$, which will aid parameterisation of other effects such as vegetative roughness.

\section{REFERENCES}

Azmon B. (1992). Manning coefficient of roughness - a case study along Soreq stream, 1971-1981. Journal of Hydrology 132(1-4): 361-377.

Bates P.D. (2000). Development and testing of a sub grid-scale model for moving-boundary hydrodynamic problems in shallow water. Hydrological processes 14: 2073-2088.

Bates P.D. and Anderson M.G. (1996). A preliminary investigation into the impact of initial conditions on flood inundation predictions using a time/space distributed sensitivity analysis. Catena 26 (2): 115134.

Bates P.D., Wilson M.D., Horritt M.S., Mason D., Holden N. and Currie C. (2006). Reach scale floodplain inundation dynamics observed using airborne Synthetic Aperture Radar imagery: data analysis and modelling. Journal of Hydrology, 328, 306- 318

Bishop Y., Fienberg S., Holland P. (1975). Discrete Multivariate Analysis: Theory and Practice. MIT Press: Cambridge, MA.

Bradbrook K.F., Lane S.N., Waller S.G. and Bates P.D. (2004). Two dimensional diffusion wave modelling of flood inundation using a simplified channel representation. International Journal of River Basin Management 3: 1-13.

Chow V.T. (1964). Handbook of Applied Hydrology, McGraw-Hill Book Company, New York. 
Chow V.T., Maidment D.R., and Mays L.W. (1988). Applied Hydrology. McGraw-Hill, Inc.: New York, USA.

Cohen J. 1960. A coefficient of agreement for nominal scales. Educational and Psychological Measurement 20: 37-40.

Dutta D., Alam J. and Umeda K. (2007). A two-dimensional hydrodynamic model for flood inundation simulation: a case study in the lower Mekong river basin. Hydrological Processes 21(9):1223-1237.

Horritt M.S. and Bates P.D. (2001a). Effects of spatial resolution on a raster based model of flood flow. Journal of Hydrology 253: 239-249.

Horritt M.S. and Bates P.D. (2001b). Predicting floodplain inundation: raster-based modeling versus the finite-element approach. Hydrological processes 15: 825-842.

Hunter N.M., Bates P.D., Horritt M.S., Wilson M.D. (2006). Improved simulation of flood flows using storage cell models, Proceedings of the Institute of Civil Engineers, Water Management 159, WMI, 9-18.

Hunter N.M.; Bates P.D.; Neelz S., Pender G., Villanueva, I., Wright N.G., Liang D., Falconer R.A., Lin B., Waller S., Crossley A.J., and Mason D.C. (2008). Benchmarking 2D hydraulic models for urban flooding. Proceedings of the Institution of Civil Engineers-Water Management 161(1):13-30.

Hunter N.M., Bates P.D., Horritt M.S. and Wilson, M.D. (2007). Simple spatially-distributed models for predicting flood inundation: a review. Geomorphology 90:208-225. 
Lane S.N. (2005). Roughness - time for a re-valuation? Earth Surface Processes and Landforms 30(2): 251-253.

Lane S.N., Hardy R.J. (2002). Porous rivers: a new way of conceptualising and modelling river and floodplain flows? In Transport phenomenain porous media. Ingham DB, Pop I (eds). Elsevier: UK.

Lane S.N., Hardy R.J., Elliott L., Ingham DB. (2002). High resolution numerical modelling of threedimensional flows over complex river bed topography. Hydrological Processes 16: 2261-72.

Lane S.N., Hardy R.J., Elliott L, Ingham D.B. (2004). Numerical modelling of flow processes over gravely-surfaces using structured grids and a numerical porosity treatment. Water Resources Research DOI:10.1029/2002WR001934.

Leonard J., Mietton M., Najib H., Gourbesville P. (2000). Rating curve modelling with Manning's equation to manage instability and improve extrapolation. Hydrological Sciences 45(5):739-750.

Manning R. (1891). On the flow of water in open channels and pipes. Transactions of the Institution of Civil Engineers of Ireland 20: 161-207.

Marks K.J. and Bates P.D. (2000). Integration of high-resolution topographic data with floodplain flow Models. Hydrological Processes 14: 2109-2122.

Mason D.C., Cobby D.M., Horritt M.S., Bates P.D. (2003). Floodplain friction parameterization in two-dimensional river flood models using vegetation heights derived from airborne scanning laser altimetry. Hydrological Processes 17: 1711-1732. 
McMillan H.K.; Brasington J. (2007). Reduced complexity strategies for modelling urban floodplain inundation. Geomorphology 90: 226-243.

Mignot E.; Paquier A.; Haider S. (2006). Modeling floods in a dense urban area using 2D shallow water equations. Journal of Hydrology 327(1-2): 186-199.

Neelz S.; Pender G. (2007). Sub grid scale parameterisation of 2D hydrodynamic models of inundation in the urban area. ACTA GEOPHYSICA 55:65-72.

Olsen N.R.B., Stokseth S. (1995). Three-dimensional numerical modelling of water flow in a river with large bed roughness. Journal of HydraulicResearch 33: 571-81.

Soares-Frazao S., Lhomme J., Guinot V. and Zech Yves. (2008). Two-dimensional shallow-water model with porosity for urban flood modelling. Journal of Hydraulic Research 46(1): 45-64.

Wilson M.D. and Atkinson P.M. (in press). The use of remotely sensed land cover to derive floodplain friction coefficients for flood inundation modelling, Hydrological Processes.

Néelz S., Pender G., Villanueva I., Wilson M.D., Wright N.G., Bates P.D., Mason D. and Whitlow C. (2006). Using remotely sensed data to support flood modelling, Proceedings of the Institution of Civil Engineers, Water Management, 159, WM1, 35-43.

Tayefi V., Lane, S.N., Hardy R.J. and Yu D. (2007). A comparison of 1D and 2D approaches to modelling flood inundation over complex upland floodplains. Hydrological Processes 21:3190-3202.

Yu D. and Lane S.N. (2006a). Urban fluvial flood modelling using a two-dimensional diffusion wave treatment: 1. Mesh resolution effects. Hydrological Processes 20:1541-1565. 
Yu D. and Lane S.N. (2006b). Urban fluvial flood modelling using a two-dimensional diffusion wave treatment: 2. Development of a sub grid-scale treatment. Hydrological Processes 20:1567-1583.

Yu D. (2005) Diffusion-based modelling of flood inundation over complex floodplains. PhD thesis, University of Leeds, UK. 


\begin{tabular}{|c|c|c|c|}
\hline $\begin{array}{l}\text { Original mesh } \\
\text { Sub mesh }\end{array}$ & $32 \mathrm{~m}$ & $16 \mathrm{~m}$ & $8 \mathrm{~m}$ \\
\hline $16 \mathrm{~m}$ & $32,2: 1$ & & \\
\hline $8 \mathrm{~m}$ & $32,4: 1$ & $16,2: 1$ & \\
\hline $4 \mathrm{~m}$ & $32,8: 1$ & $16,4: 1$ & $8,2: 1$ \\
\hline
\end{tabular}

Table 1: combinations of meshes with different coarsening ratio. 


\begin{tabular}{l|cc|cc|cc}
\hline & \multicolumn{2}{|l|}{ Overall accuracy } & \multicolumn{2}{l}{$\begin{array}{l}\text { Conditional Kappa for wet } \\
\text { cells }\end{array}$} & F statistic & \\
\cline { 2 - 7 } & interpolated & $\begin{array}{l}\text { Post- } \\
\text { processed }\end{array}$ & interpolated & $\begin{array}{l}\text { Post- } \\
\text { processed }\end{array}$ & interpolated & $\begin{array}{l}\text { Post- } \\
\text { processed }\end{array}$ \\
\hline $32 \mathrm{~m}$ & 0.89 & 0.89 & 0.83 & 0.83 & 0.56 & 0.54 \\
$32 \mathrm{~m}, 2: 1$ & 0.90 & 0.90 & 0.88 & 0.87 & 0.57 & 0.56 \\
$32 \mathrm{~m}, 4: 1$ & 0.90 & 0.90 & 0.90 & 0.88 & 0.57 & 0.56 \\
$32 \mathrm{~m}, 8: 1$ & 0.89 & 0.89 & 0.88 & 0.86 & 0.56 & 0.54 \\
$16 \mathrm{~m}$ & 0.89 & 0.89 & 0.84 & 0.82 & 0.55 & 0.54 \\
$16 \mathrm{~m}, 2: 1$ & 0.90 & 0.90 & 0.91 & 0.88 & 0.58 & 0.56 \\
$16 \mathrm{~m}, 4: 1$ & 0.89 & 0.89 & 0.90 & 0.88 & 0.56 & 0.57 \\
$8 \mathrm{~m}$ & 0.88 & 0.88 & 0.83 & 0.82 & 0.54 & 0.54 \\
$8 \mathrm{~m}, 2: 1$ & 0.89 & 0.89 & 0.90 & 0.89 & 0.56 & 0.55 \\
\hline
\end{tabular}

Table 2: Accuracy statistics obtained from model validation. Left column: results obtained with directly-interpolated meshes; Right column: results obtained with meshes post-processed to introduce walls. 


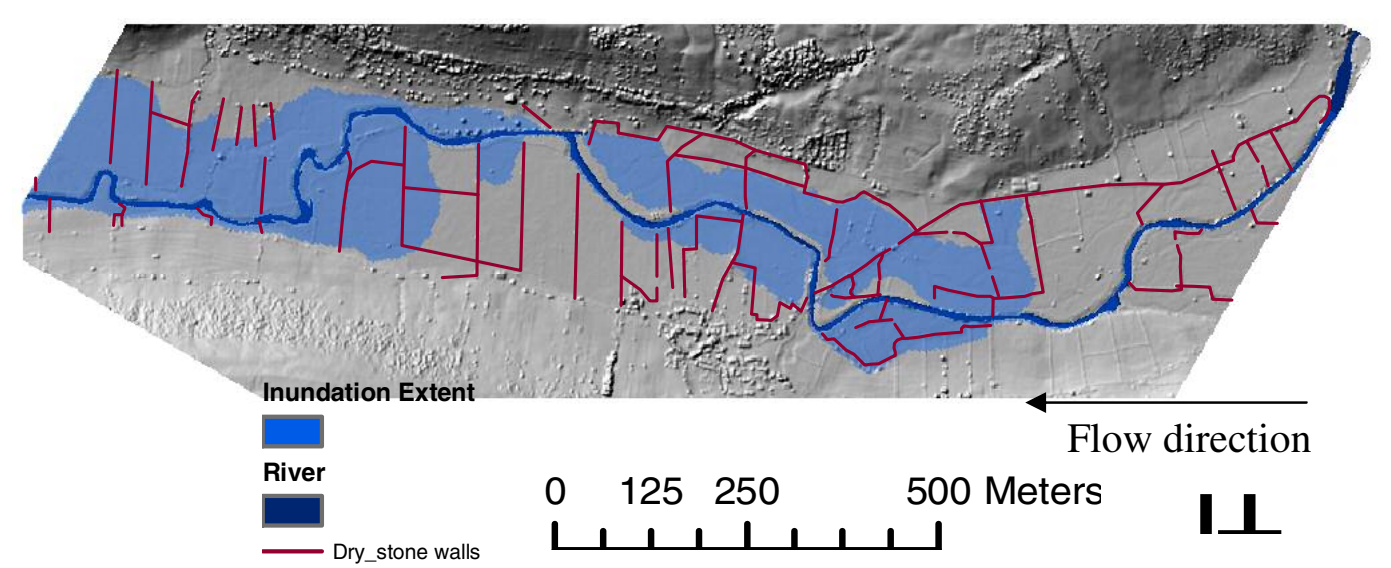

Figure 1: Floodplain topography (shaded DEM) with observed max inundation extent. 


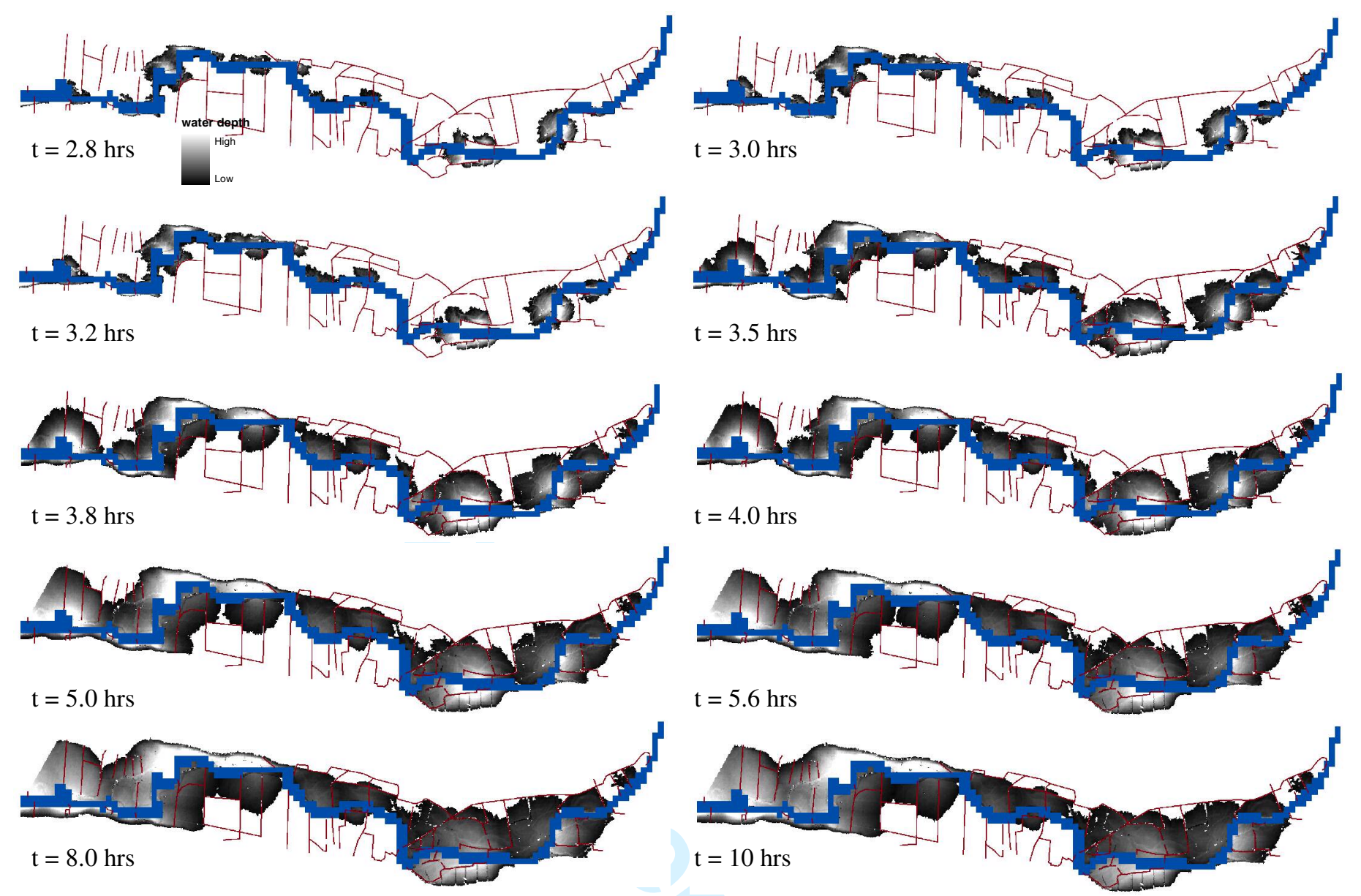

Figure 2: Inundation extent over time predicted by the $4 \mathrm{~m}$ simulation with a Manning's value of 0.06. 


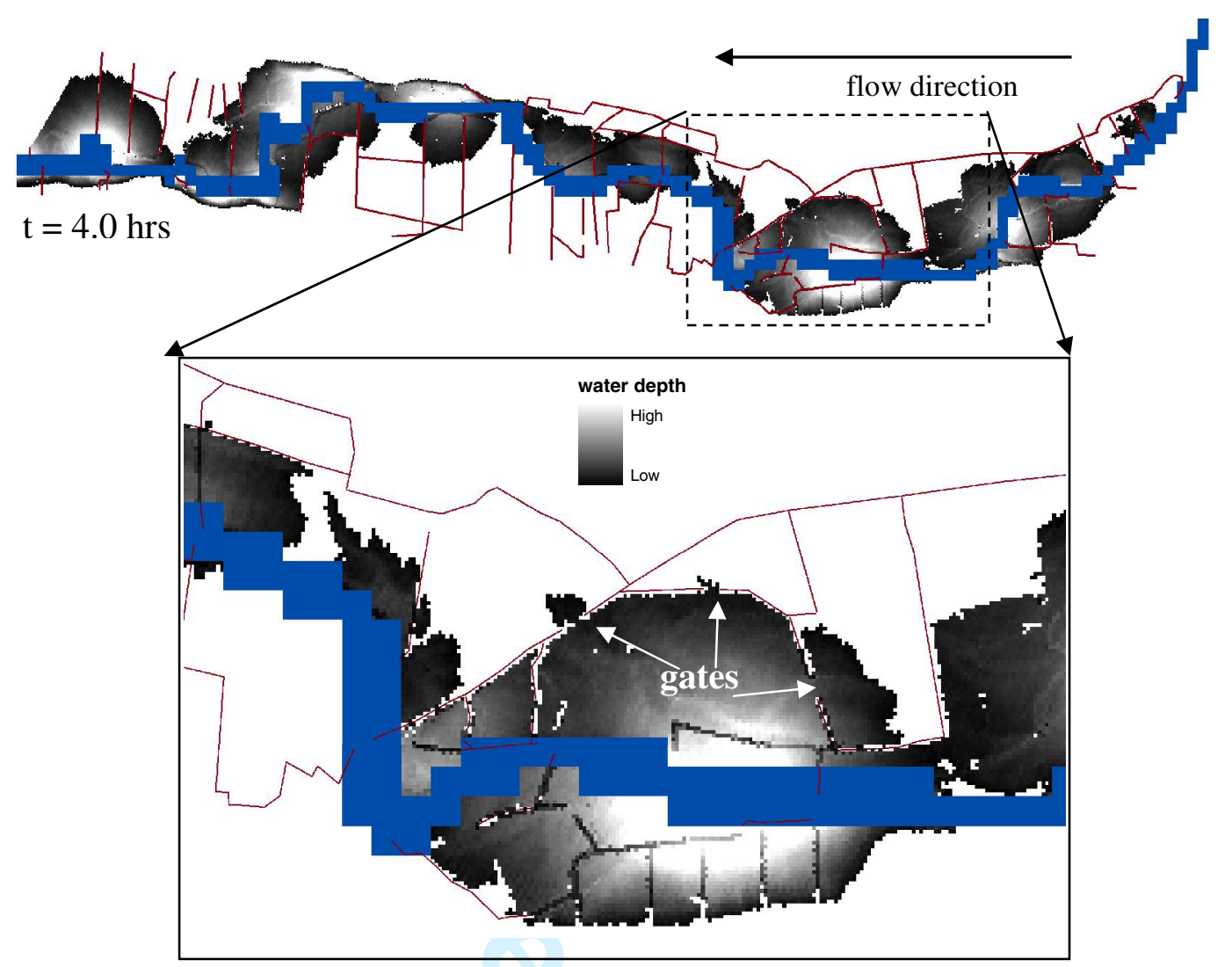

Figure 3: Effect of dry stone walls on flow routing. 


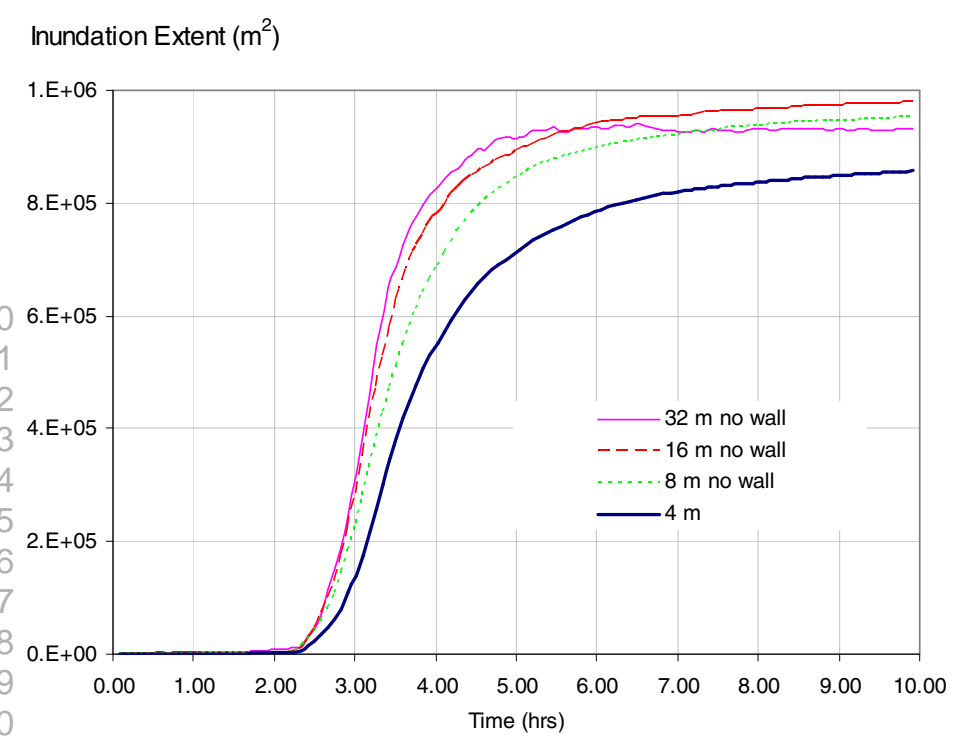

(a)

Inundation Extent $\left(\mathrm{m}^{2}\right)$

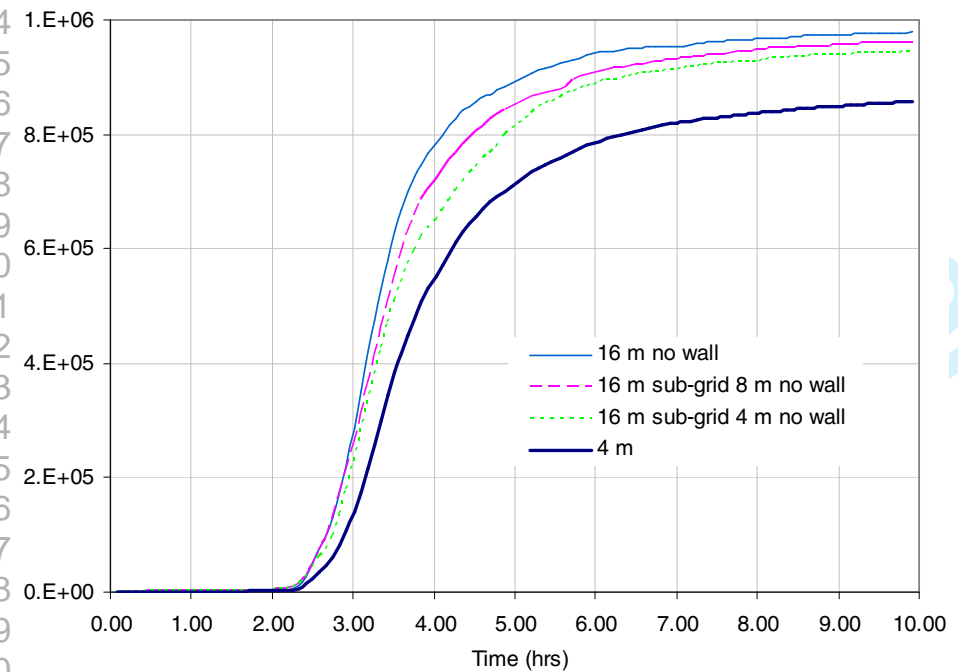

(c)

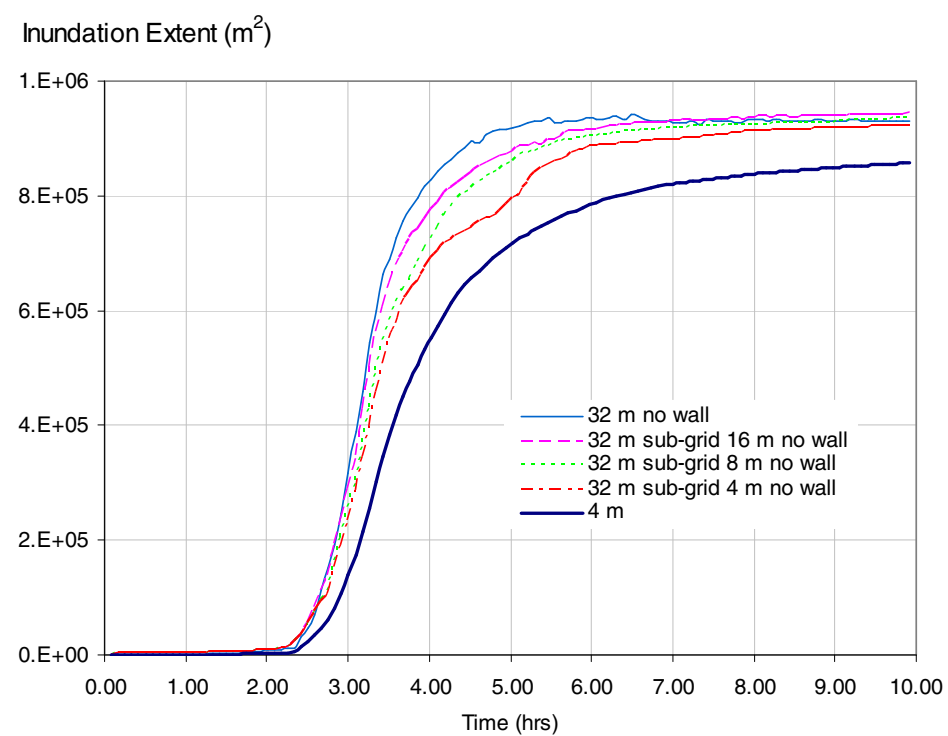

(b)

Inundation Extent $\left(\mathrm{m}^{2}\right)$

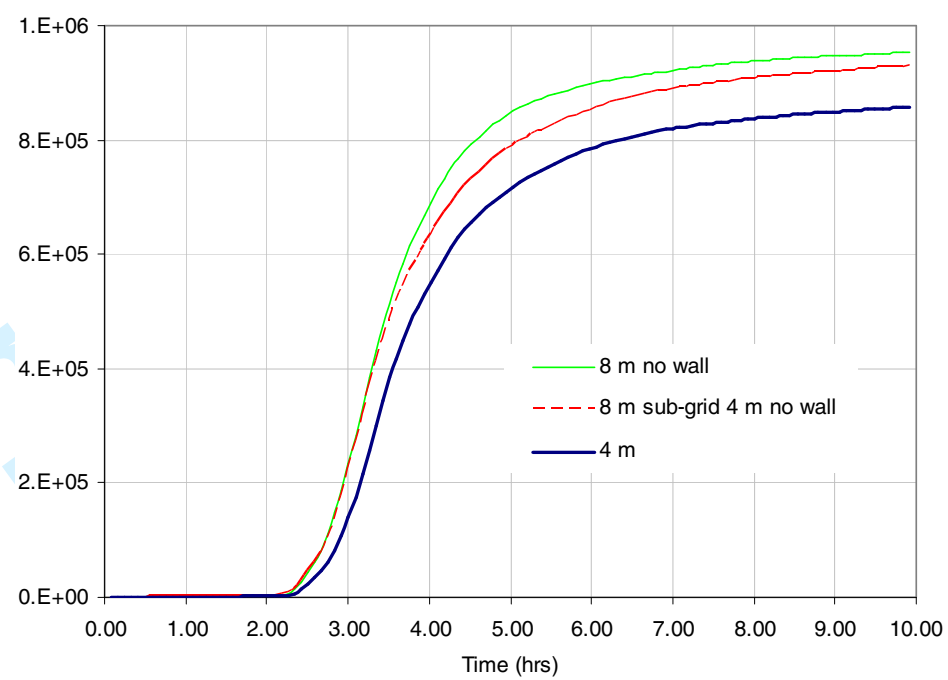

(d)

Figure 4: Inundation area versus time with different mesh resolutions and sub grid scale treatments.

Obtained with directly-interpolated meshes. (a) simulations with normal treatment; (b) $32 \mathrm{~m}$

simulation with and without sub grid treatment; $(c) 16 \mathrm{~m}$ simulation with and without sub grid

treatment; (b) $8 \mathrm{~m}$ simulation with and without sub grid treatment 
(a) $32 \mathrm{~m}$ with wall

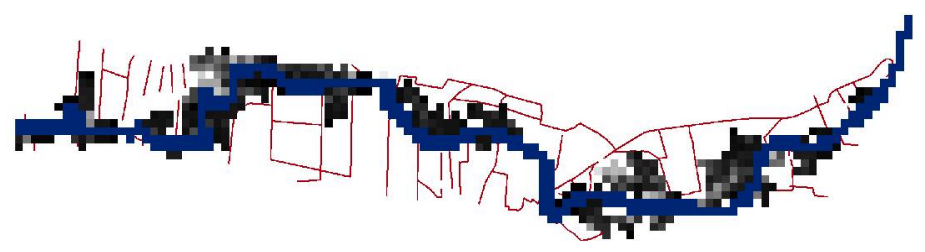

$3.0 \mathrm{hrs}$

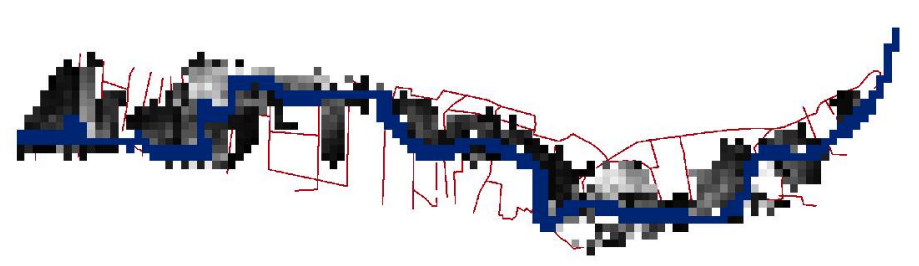

$3.25 \mathrm{hrs}$

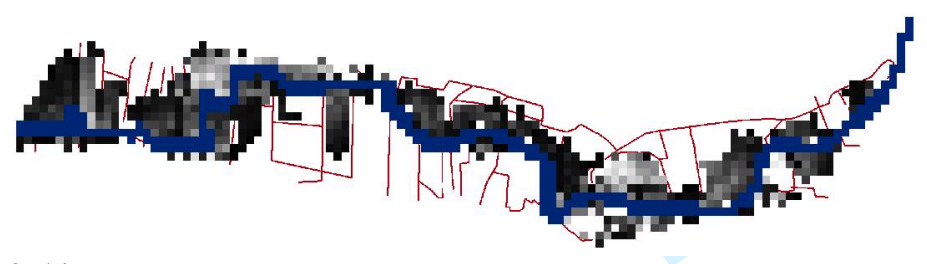

$3.5 \mathrm{hrs}$

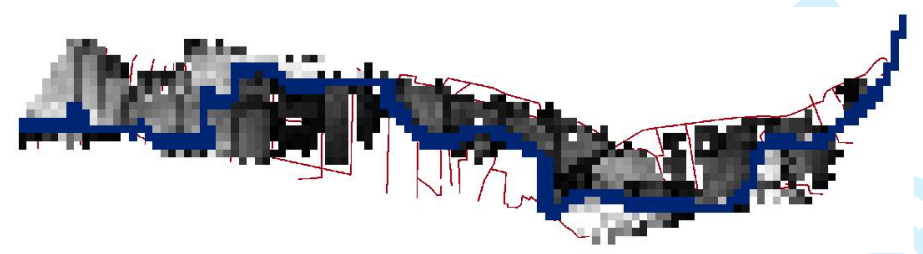

$4.5 \mathrm{hrs}$ (b) $32 \mathrm{~m}$ without wall

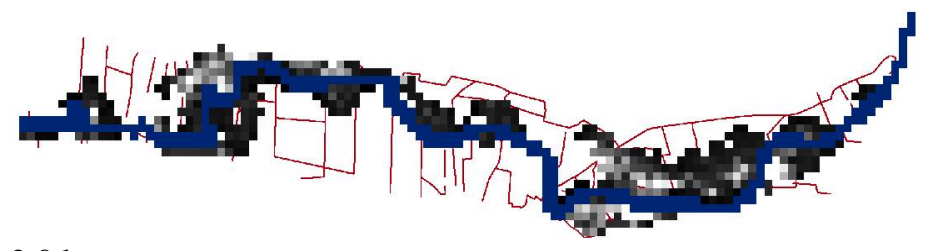

$3.0 \mathrm{hrs}$

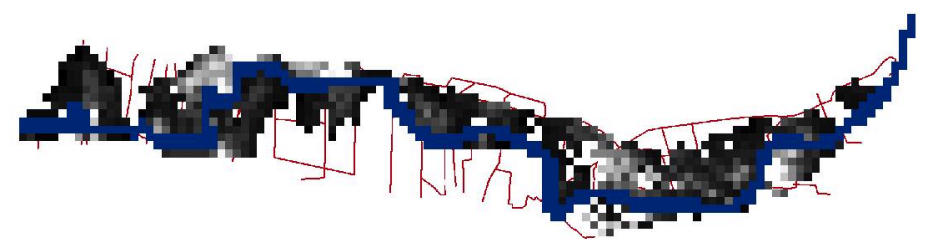

$3.25 \mathrm{hrs}$

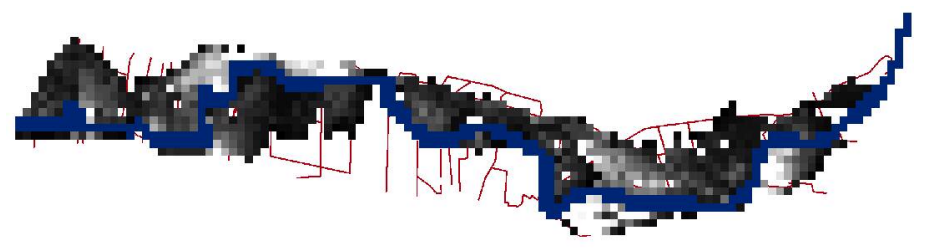

$3.5 \mathrm{hrs}$

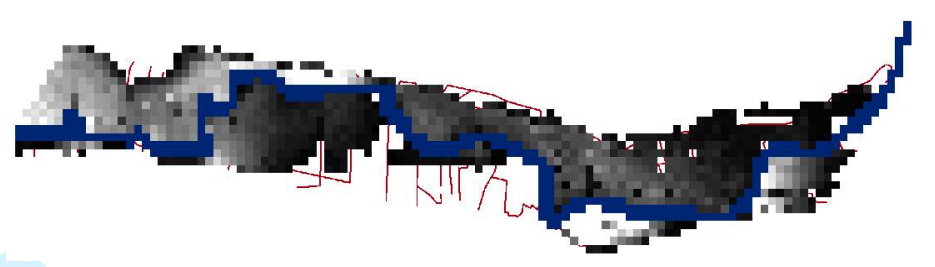

$4.5 \mathrm{hrs}$

Figure 5: Inundated areas from 3.0 hrs to 4.5 hrs for simulations with and without post-processing 


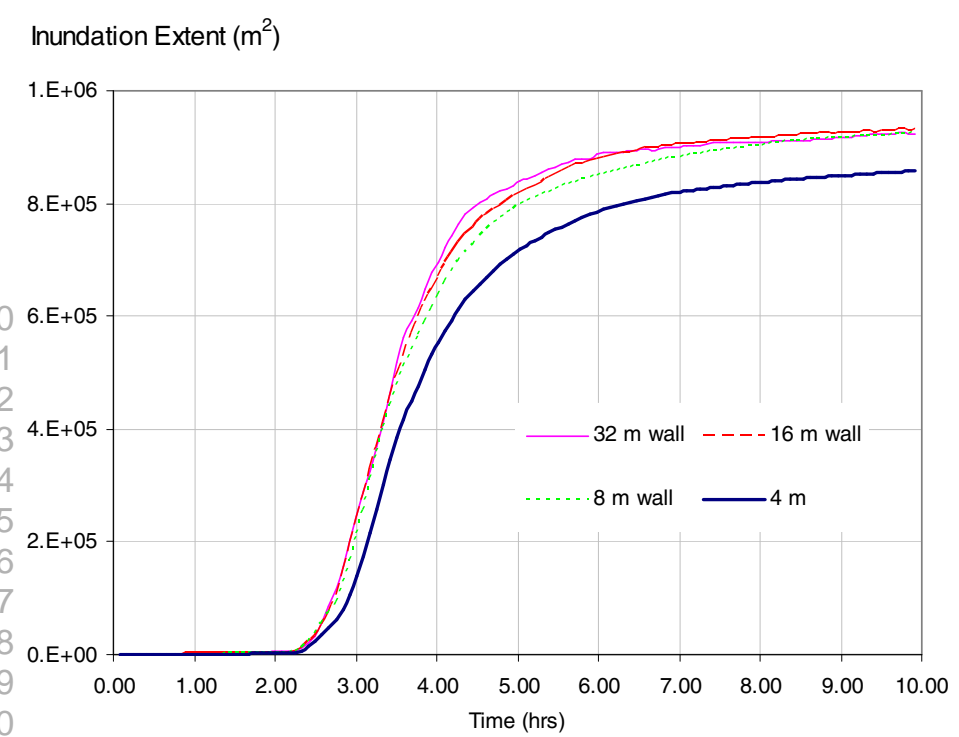

(a)

Inundation Extent $\left(\mathrm{m}^{2}\right)$

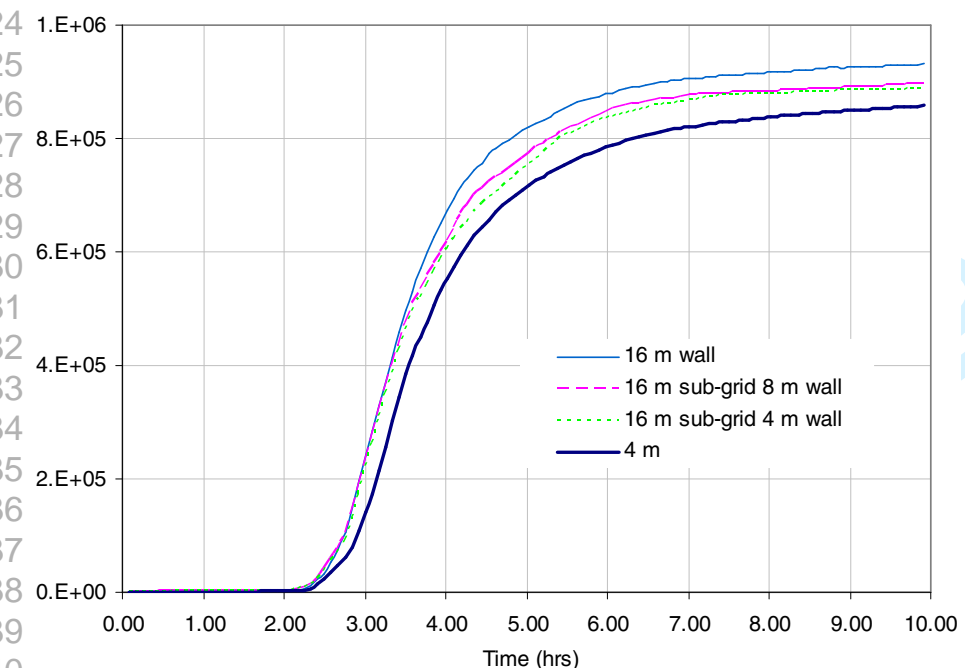

(c)

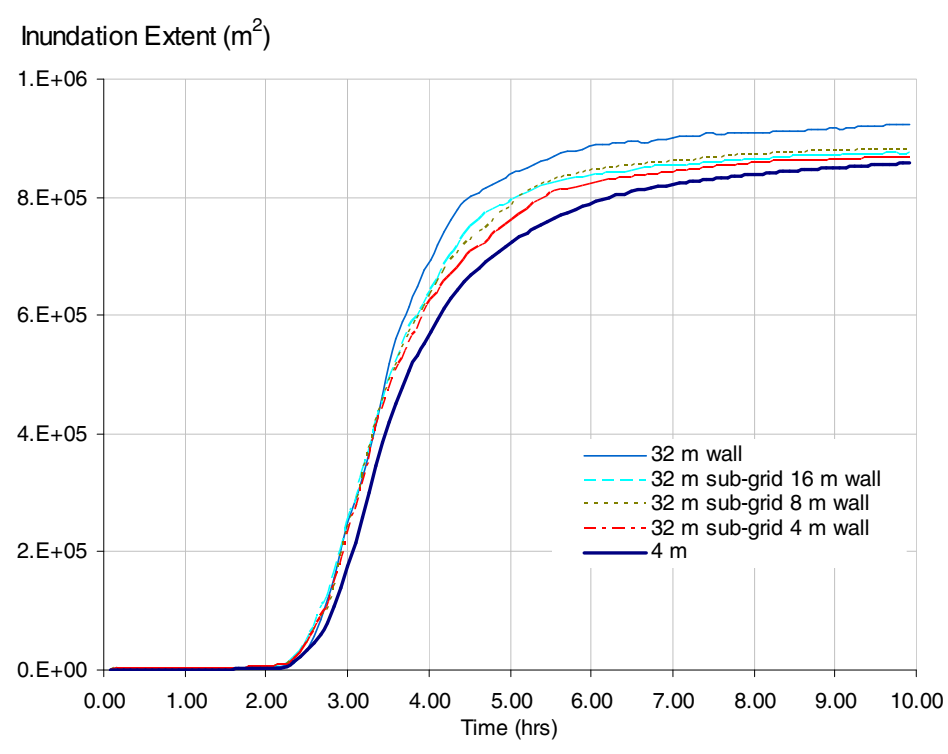

(b)

Inundation Extent $\left(\mathrm{m}^{2}\right)$

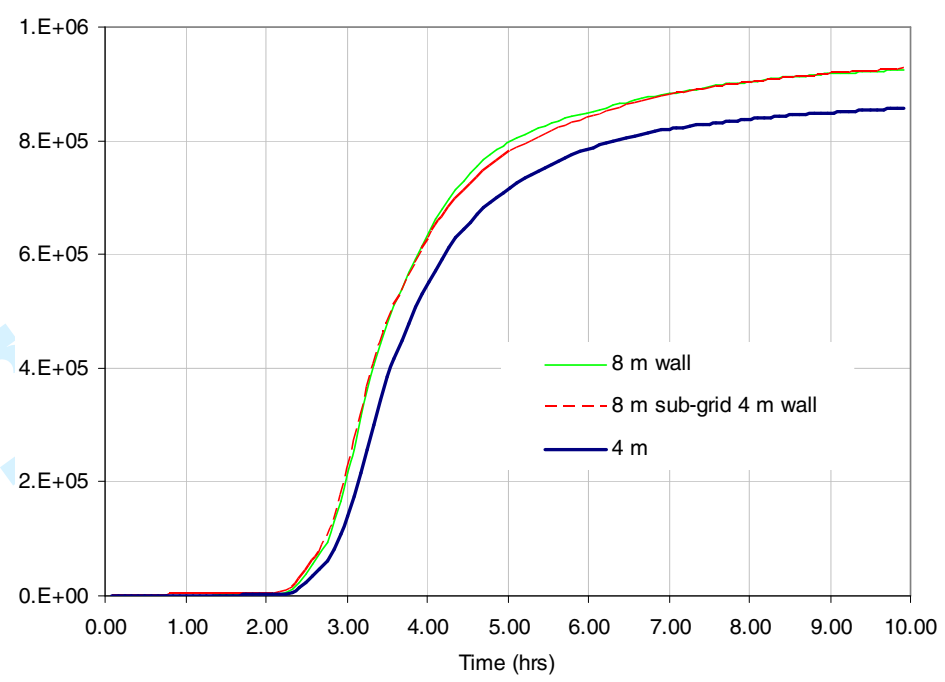

(d)

Figure 6: Inundation area versus time with different mesh resolutions and sub grid scale treatments.

Obtained with post-processed topographies with walls built in. (a) simulations with normal treatment;

(b) $32 \mathrm{~m}$ simulation with and without sub grid treatment; (c) $16 \mathrm{~m}$ simulation with and without sub grid treatment; (b) 8 m simulation with and without sub grid treatment. 
(a) Overall accuracy

$32 \mathrm{~m}$

Overall Accuracy
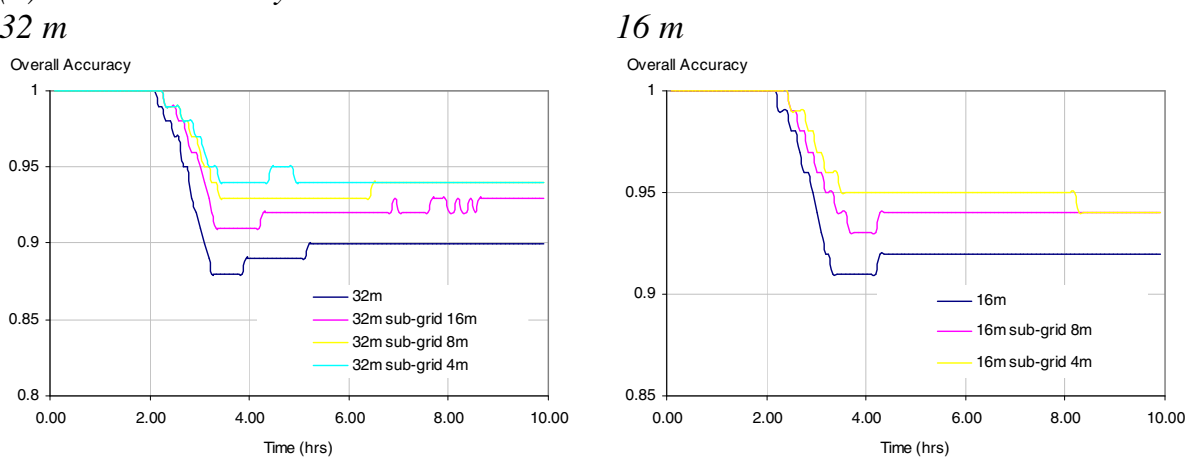

$8 m$

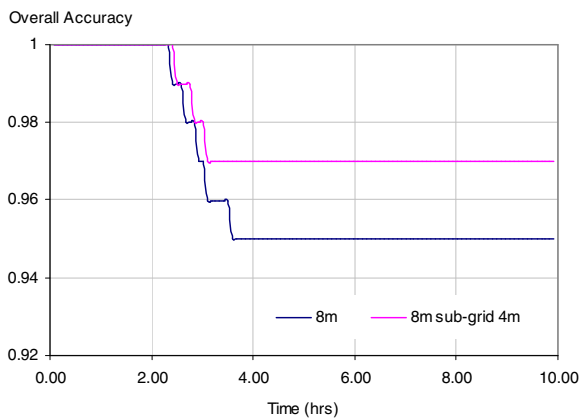

(b) Conditional Kappa for wet cells

$1532 \mathrm{~m}$

16 kappa for w we cells

17

18

19

20

21

28 (c) F statistic

$2932 \mathrm{~m}$

$30 \quad F$ Statistic

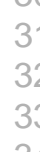

32

33

34 。

60 with walls explicitly built-in: (d) F statistics.
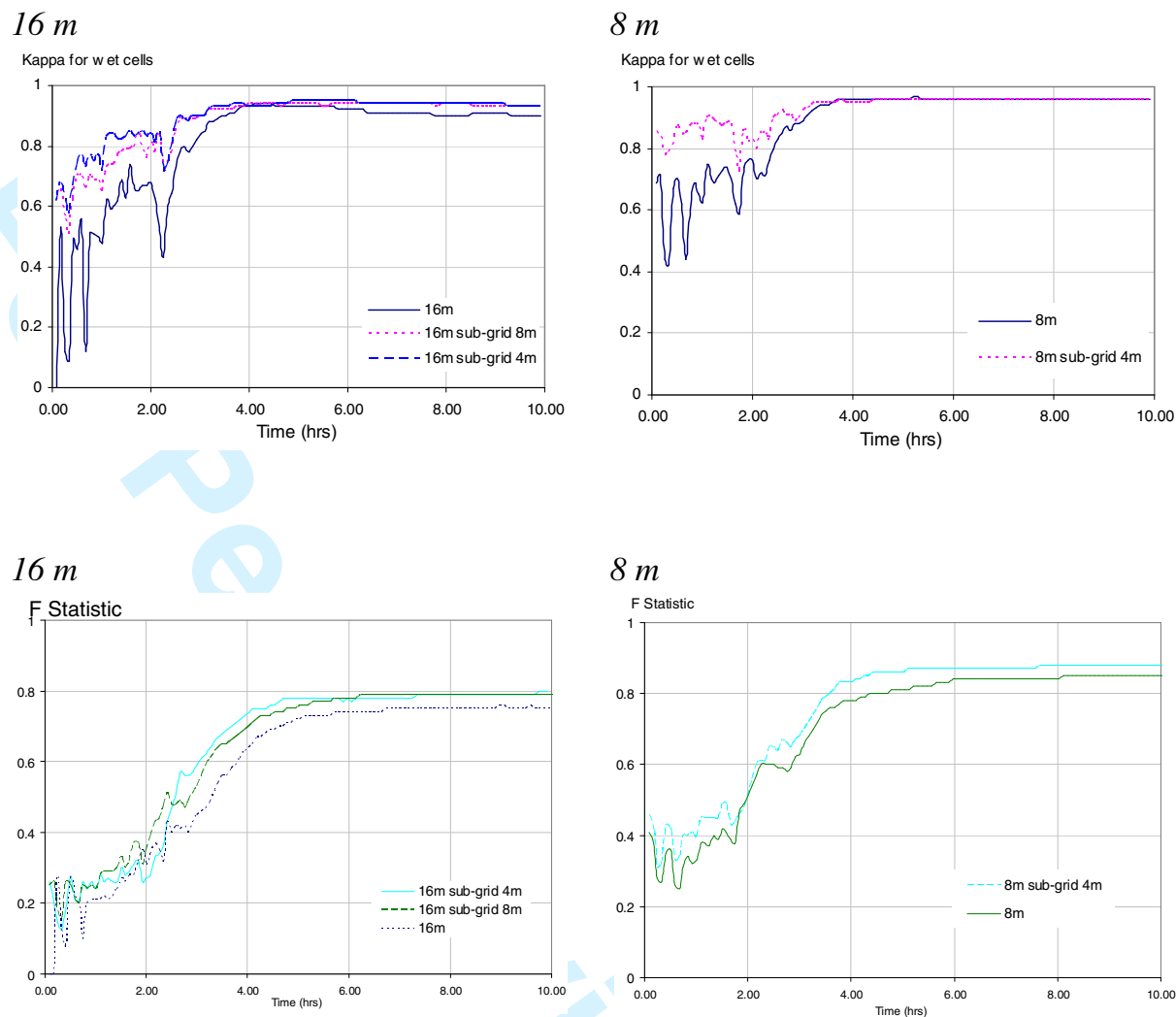

d) F statistic for simulations - post-processed with walls built in
$32 m$

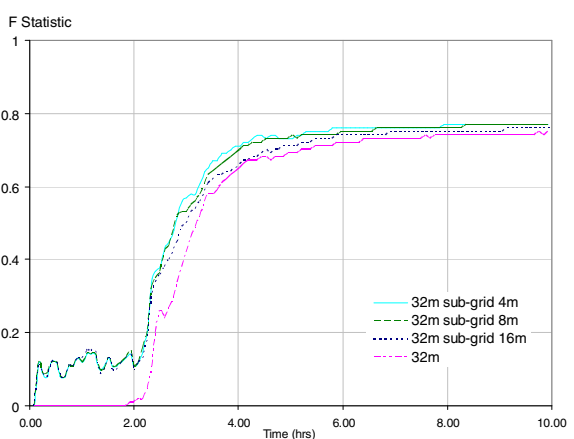

$16 \mathrm{~m}$

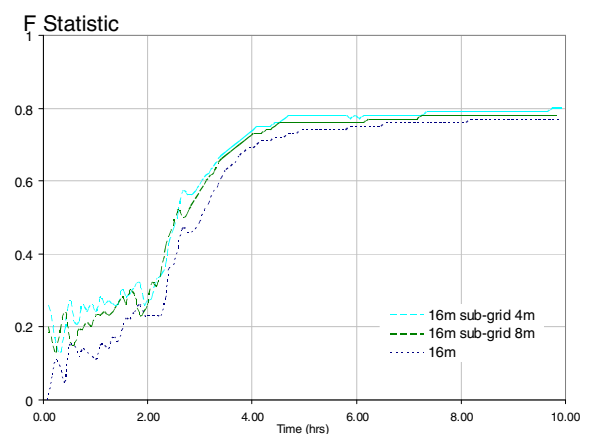

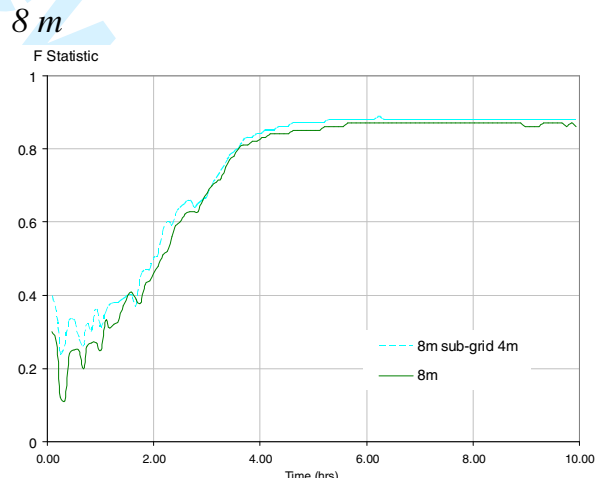

Figure 7: Accuracy statistics obtained from model verification for all model resolutions. For directly-interpolated meshes: (a) overall accuracy; (b) conditional Kappa for wet cells; (c) F statistic; and for post-processed meshes $32 \mathrm{~m}$ sub-grid $4 \mathrm{~m}$
$-32 \mathrm{~m}$ sub-grid $8 \mathrm{~m}$
$.32 \mathrm{~m}$ sub-grid $16 \mathrm{~m}$
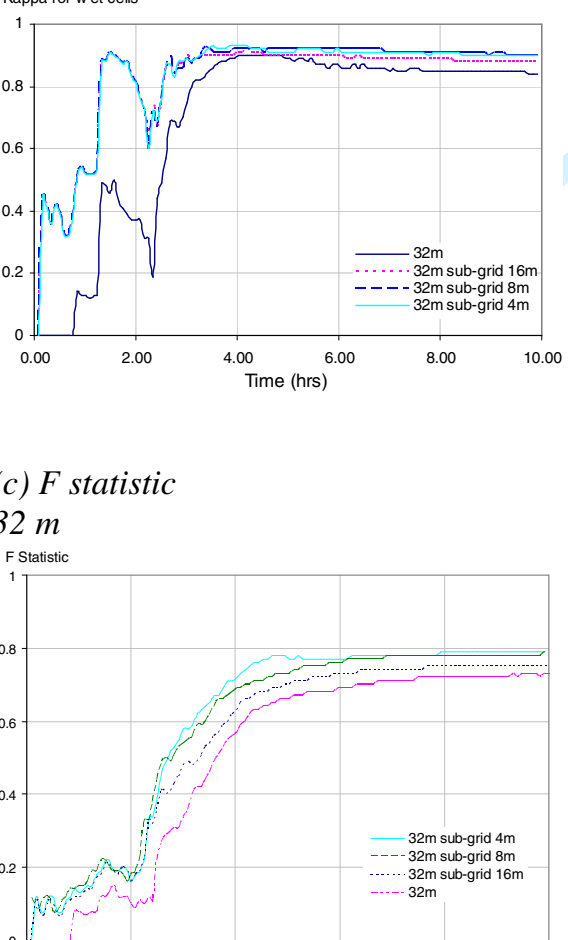


\section{Page 33 of 33}

(a)

Inundatation area $\left(\mathrm{sq} \mathrm{m}^{2}\right)$

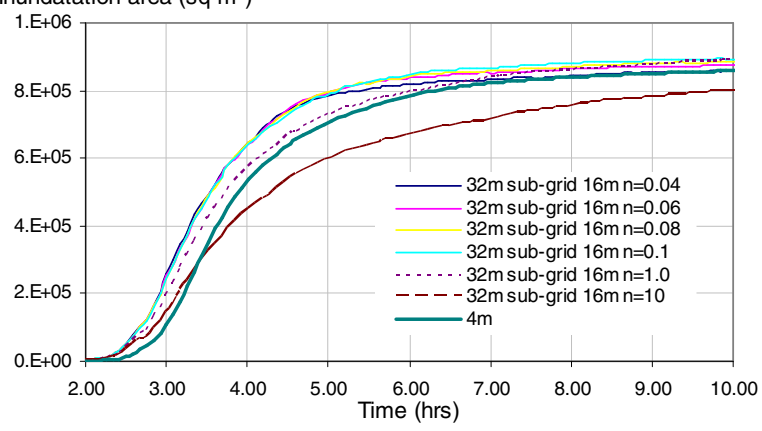

10

11
Inundatation area $\left(\mathrm{sq} \mathrm{m}^{2}\right)$

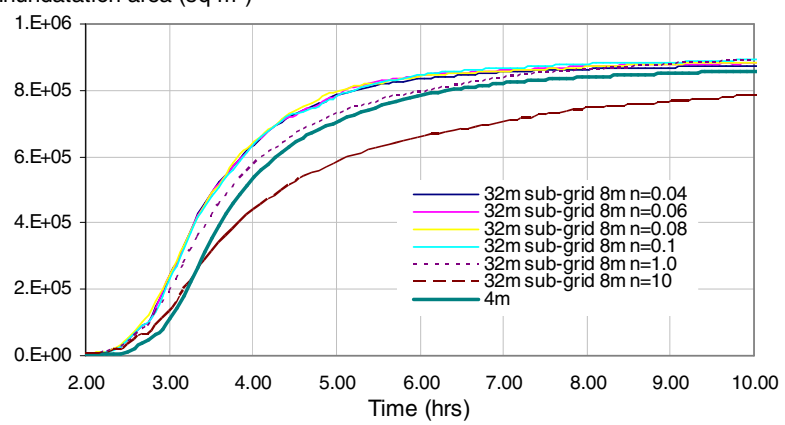

Inundatation area $\left(\mathrm{sq} \mathrm{m}^{2}\right)$

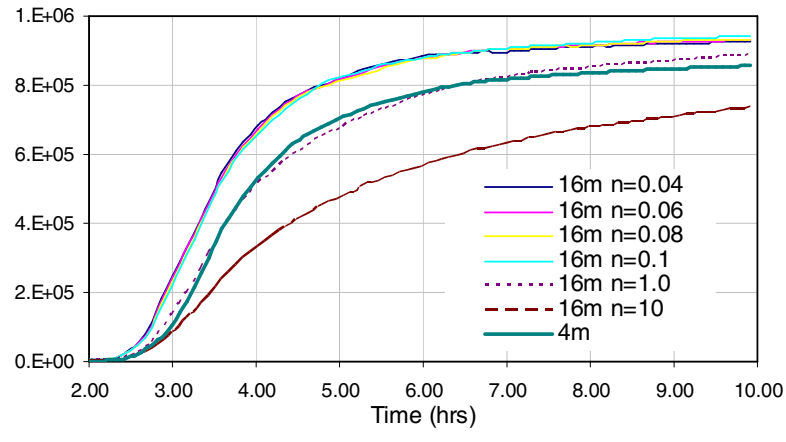

Inundatation area $\left(\mathrm{sq} \mathrm{m}^{2}\right)$

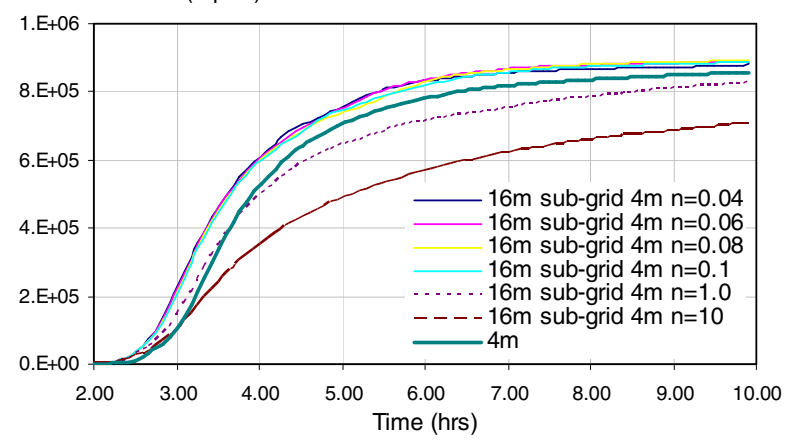

Inundatation area (sq m²)

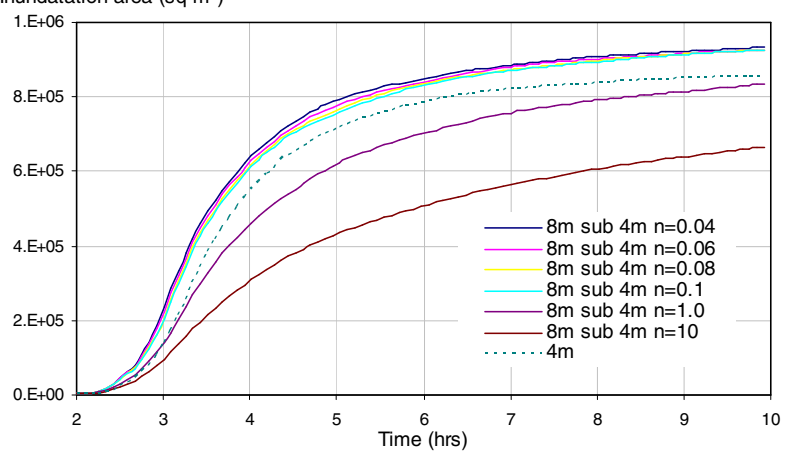

(b)

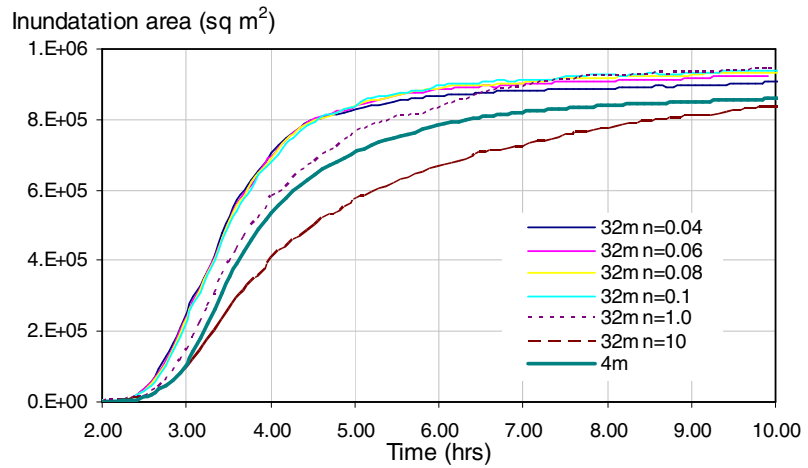

Inundatation area $\left(\mathrm{sq} \mathrm{m}^{2}\right)$

(d)

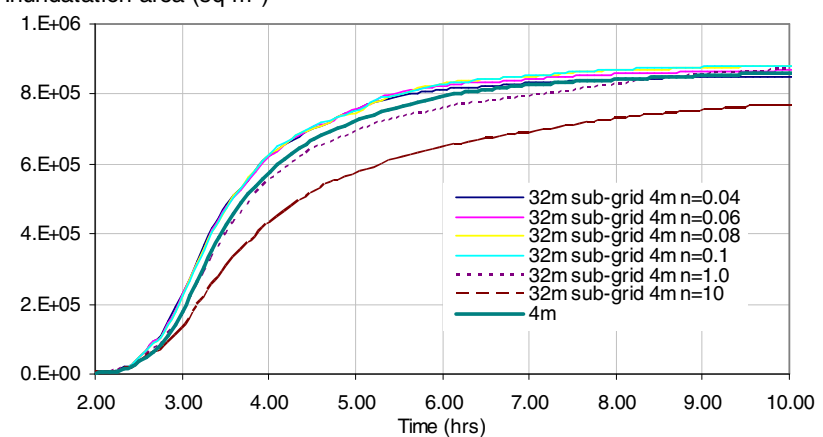

(f)

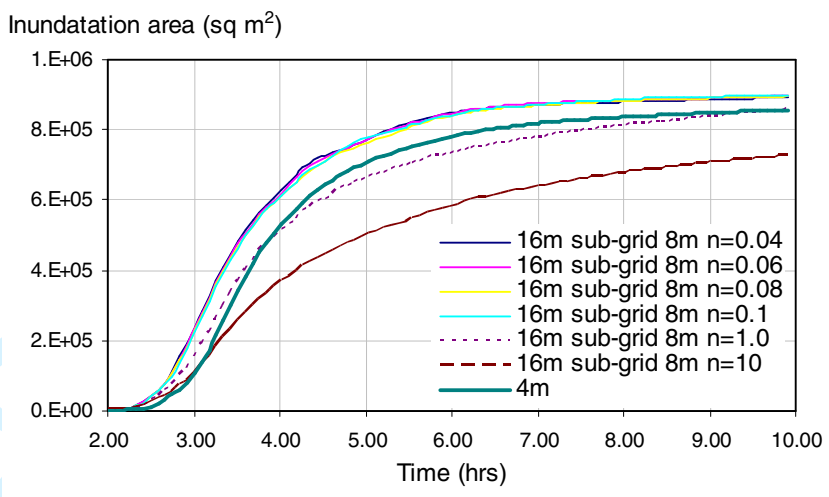

(h)

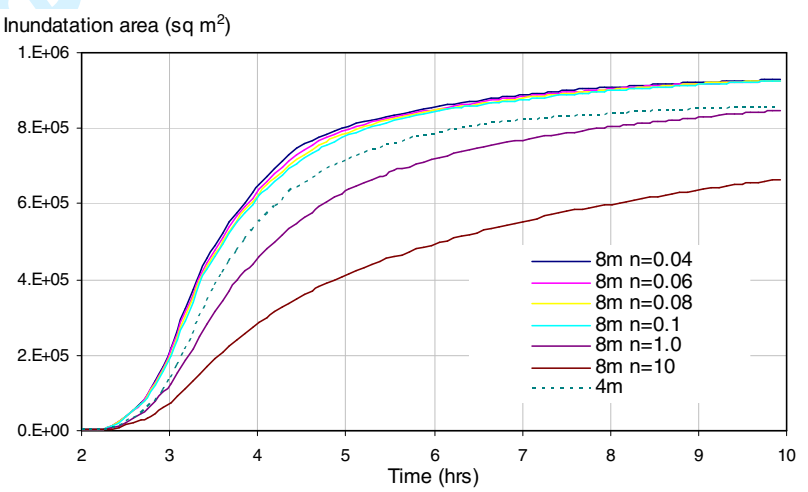

(j)

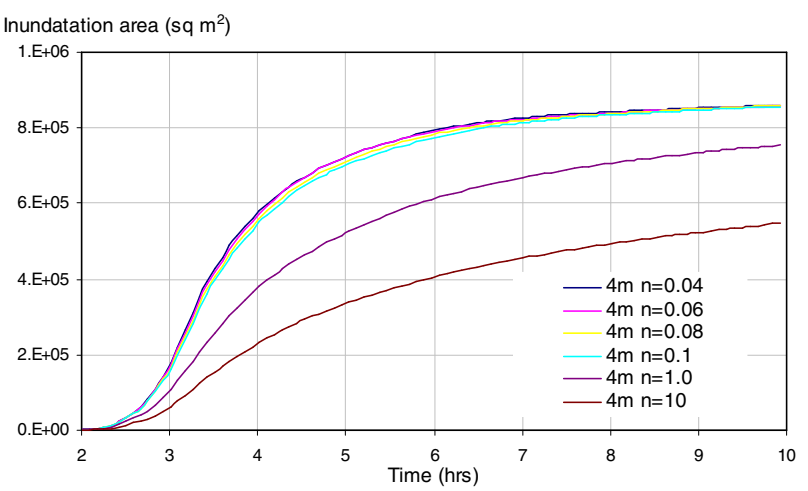

Figure 8: Predictions of inundated area through time with different mesh resolutions and values of Manning's 